\title{
Is there Space for "Genuine Autonomy" for Tibetan Areas in the PRC's System of Nationalities Regional Autonomy?
}

[For publication in International Journal on Minority and Group Rights, 2010]

\section{Yash Ghai, Kelley Loper and Sophia Woodman*}

This article considers whether room exists within the current system of national regional autonomy (NRA) in China to accommodate Tibetan aspirations for "genuine autonomy" under PRC sovereignty. It examines the legal framework for NRA in China, as well as Chinese government policy and practice toward autonomous areas, in terms of the limitations and possibilities they imply for realizing Tibetan aspirations for autonomy, highlighting specific areas of concern, opportunities and constraints. It explores the development of political and legal approaches toward autonomy since the 1930s, the nature of the current existing framework and how recent legal and political developments interact with that framework. It looks at options for autonomy under the Chinese Constitution and national legislation, particularly the selfgovernment of nationality (minority) autonomous areas as well as Article 31 of the Constitution which has provided the basis for the establishment of special administrative regions (SARs). Since autonomous areas also exercise the general powers of local governments in the PRC, it describes the general system of local government at the provincial and lower administrative levels. The article examines the practical implementation and operation of minority autonomy and SARs including the apparent gap between law and practice. In particular, special attention is paid to the role of the Chinese Communist Party (CCP) and its officials which have a significant impact on the exercise of state powers. It concludes that there are formidable obstacles to the autonomy that Tibetan seek in order to preserve their culture, values and identity.

\section{China, Tibet, Nationalities, Autonomy}

\section{Introduction}

\footnotetext{
* Yash Ghai is Professor Emeritus, University of Hong Kong, Kelley Loper is Assistant Professor and Director of the Human Rights LL.M. programme at the University of Hong Kong, Sophia Woodman is a PhD candidate in sociology at the University of British Columbia
} 
Initiatives toward negotiations between representatives of the Dalai Lama and Beijing have stopped and started several times since the 1980s, but little progress has been made. Significant differences still exist between the Chinese and Tibetan positions and prospects for meaningful developments in the short term appear unpromising. ${ }^{1}$ Most recently, talks between Tibetan exiles and Beijing in July and November 2008 failed to achieve results and the Tibetan exile community, which met in India later in November 2008, has decided to stop sending envoys to meet with Chinese authorities, although it has reaffirmed non-violence and a "Middle Way Approach". At the same time, tensions within Tibetan areas in the People's Republic of China (PRC) remain high. Violent protests erupted in March 2008, followed by a crackdown, and the public security bureau in Lhasa has reportedly detained more than 81 people in a "strike hard" campaign launched in January 2009, possibly to forestall demonstrations marking the 50 anniversary of the suppression of a Tibetan uprising in March $1959 .^{2}$

Beijing insists that any solution to the "Tibet question" must be found within the existing system, based on provisions in the Constitution, the Law on National Regional Autonomy (LNRA), and policy documents. ${ }^{3}$ The Tibetans are demanding "genuine autonomy", a concept first articulated by the Dalai Lama in Strasbourg in 1988 and most recently presented in a "Memorandum on Genuine Autonomy" during discussions on 4 and 5 November 2008 in Beijing. ${ }^{4}$

\footnotetext{
${ }^{1}$ See Shi Jiangtao, “'Middle Way” Unlikely to Bring Softer Stance', South China Morning Post, 24 November 2008, p. 6 and Recommendation of the First Special General Meeting Convened Under Article 59 of the Charter, 22 November 2008, available at: <www.tibet.net/en/index.php?id=595\&articletype=flash\&rmenuid=morenews $>$. ${ }^{2}$ Associated Press, 'China Detains 81 People in Crackdown: Media', 27 January 2009.

${ }^{3}$ For a discussion of Beijing's position on - and reasons for rejection of - the Dalai Lama's proposal, see He Baogang, 'The Dalai Lama's Autonomy Proposal', in B. Sautman and J. T. Dreyer (eds.), Contemporary Tibet: Politics, Development and Society in a Disputed Region (2006) 67-84.

${ }^{4}$ Memorandum on Genuine Autonomy for the Tibetan People, 2008, available at:

$<$ www.tibet.net/en/index.php?id=78\&articletype=press $>$. See also The Department of Information and International Relations (DIIR), The Middle-Way Approach: A Framework For Resolving The Issue Of Tibet, The Central Tibetan Administration, available at: <www.tibet.net/en/diir/sino/std/imwa.html $>$, updated August 2006, and Address to Members of the European Parliament by His Holiness the Dalai Lama, 15 June 1988, Tibet Justice Center, available at: <www.tibetjustice.org/materials/tibet/tibet4.html $>$. The key features of the "Middle Way Approach" include the establishment of a Tibetan political entity "comprising the three traditional provinces of Tibet"; genuine national regional autonomy; an elected legislature and executive and an independent judiciary; eventual transformation of Tibet into a zone of peace with limited Chinese forces based in Tibet in the meantime; China would have responsibility only for the "political aspects of Tibet's international relations and defense"; and an end to human rights violations and the policy of population transfer of Han Chinese into Tibetan areas.
} 
This article considers whether room exists within the current system of national regional autonomy (NRA) in China to accommodate Tibetan aspirations for "genuine autonomy" under PRC sovereignty. It examines the legal framework for NRA in China, as well as Chinese government policy and practice toward autonomous areas, in terms of the limitations and possibilities they imply for realizing Tibetan aspirations for autonomy, highlighting specific areas of concern, opportunities and constraints. It explores the development of political and legal approaches toward autonomy since the 1930s, the nature of the current existing framework and how recent legal and political developments interact with that framework. It looks at options for autonomy under the Chinese Constitution and national legislation, particularly the selfgovernment of nationality (minority) autonomous areas as well as Article 31 of the Constitution which has provided the basis for the establishment of special administrative regions (SARs). Since autonomous areas also exercise the general powers of local governments in the PRC, it describes the general system of local government at the provincial and lower administrative levels. The article examines the practical implementation and operation of minority autonomy and SARs including the apparent gap between law and practice. In particular, special attention is paid to the role of the Chinese Communist Party (CCP) and its officials which have a significant impact on the exercise of state powers.

The current weak status of the rule of law in China, the lack of a democratic political system, as well as state priorities emphasizing unity, sovereignty, CCP control, and economic development create considerable obstacles for realizing genuine autonomy within the existing system. $^{5}$ The preoccupation with sovereignty and centralisation of power fails to provide an effective guarantee of the distribution or sharing of power, reducing "autonomy" purely to an administrative device.

These limitations are reflected in the language of the laws and regulations themselves as well as in apparent breaches of the legal provisions and the functioning of the system in practice. For example, NRA does not designate matters, such as culture, in which the central authorities cannot interfere. The constraints are also inextricably linked to the ultimate objectives of the NRA system. Autonomy is the centrepiece of China's ethnic policy, designed both to hold its minority communities together and to expand its jurisdiction through the re-unification of

\footnotetext{
${ }^{5}$ Y. P. Ghai, Hong Kong's New Constitutional Order: The Resumption of Chinese Sovereignty and the Basic Law (1999) pp. 137-188 and Y. P. Ghai, 'Autonomy Regimes in China: Coping with Ethnic and Economic Diversity', in Y. P. Ghai (ed.), Autonomy and Ethnicity: Negotiating Competing Claims in Multi-Ethnic States (2000) pp. 77-98.
} 
Greater China. Its aims have included securing the cooperation of border regions; the eventual political and cultural integration of these regions and ensuring stability. The process of legalization of autonomy policy has been an attempt to lend legitimacy and predictability to government policies rather than to make significant changes in relations between minority areas and the central government. ${ }^{6}$ Some of these constraints on minority autonomy also apply to Hong Kong and Macao as special administrative regions established on the basis of Article 31 of the Constitution. Indeed, although Article 31 seems to provide potential flexibility for structuring autonomy options - and reflects the original meaning of NRA, as promised in the 1952 General Program for the Implementation of Regional Autonomy for Minorities (General Programme) and an agreement reached between Beijing and Tibet in 1951 - political realities suggest that its application is unlikely in the Tibetan context.

There seems to be agreement among scholars that the limitations of the NRA framework - and the Chinese government's insistence on the continuation of this system - render Tibetan hopes for genuine autonomy improbable under current conditions. Some have argued that the NRA system grants significant autonomy in the areas of culture, language and economy, although there are problems with its enforcement. ${ }^{7}$ Despite the limitations, others believe that negotiating the future of Tibet within the existing system may be a more realistic position than a rejection of the legal and political framework which could effectively end any impetus for negotiations. Sautman claims that China has not taken the Dalai Lama's call for genuine autonomy seriously, in part because Beijing believes he wants to "completely negate the value of the existing system of ethnic regional autonomy in Tibet". ${ }^{8}$ He and Sautman assert that a useful focus for negotiations would be "improving" the current system so that the autonomy it envisages may be exercised to the fullest possible extent. ${ }^{9}$ Some suggest emphasizing the benefits of resolution and the potential costs of delaying negotiations, ${ }^{10}$ while reassuring Beijing that Tibetan proposals pose no threat to the sovereignty and integrity of the Chinese state.

\footnotetext{
${ }^{6}$ P. B. Potter, 'Governance of the Periphery: Balancing Local Autonomy and National Unity', 19 Colum. J. Asian L. (2005) pp. 294-296.

${ }^{7}$ C. P. Mackerras, China's Minorities: Integration and Modernization in the Twentieth Century (1994) pp. 153-166 and 264-265.

${ }^{8}$ B. Sautman, 'Resolving the Tibet Question: Problems and Prospects', 11 Journal of Contemporary China (2002) p. 82.

${ }^{9}$ He Baogang, and B. Sautman, 'The Politics of the Dalai Lama's New Initiative for Autonomy', 78 Pacific Affairs (2005).

${ }^{10}$ T. Rabgey and T. W. Sharlho, 'Sino-Tibetan Dialogue in the Post-Mao Era', East-West Center, Policy Studies 12, Washington, 2004, p. 28.
} 
Precedents could be drawn from other countries which have attempted to balance national and local concerns through a variety of forms of autonomy. ${ }^{11}$

The article concludes, however, that neither NRA nor the Article 31 framework is adequate for the accommodation of the aspirations and specific needs of Tibetans, and that it would be desirable to negotiate on the basis of the unique situation of Tibet, the specificity of its historical connections with China, and its distinctive religious and cultural traditions. Quite apart from minority issues, Chinese scholars and policy makers have started to discuss constitutional reforms to deal with the political, economic and social changes of the last two decades, in which stronger judicial institutions, greater distribution of power, and democratization feature prominently. While the current system presents opportunities, it also contains flaws which inhibit the fulfilment of Tibetan aspirations for genuine autonomy and, therefore, can only provide real autonomy by altering the legal and policy framework.

Part 2 of the article reviews China's autonomy in policy and law from the 1930s to the 1990s; part 3 assesses the current legal framework; part 4 examines the operation of the national minority autonomy in practice including the workings of political representation, the role of the Communist Party, the exercise of local and autonomous legislative powers, and regulations and policy related to religion and language. Part 5 presents conclusions as well as possibilities for the way forward.

\section{China's Autonomy Policy and Law from the 1930s to the 1990s}

The PRC's policy toward minority groups has consistently aimed at gradually integrating minorities and border regions more thoroughly into a unified multi-ethnic state. As such, minority and autonomy arrangements have often been conceived of as temporary, although possibly long-term, transitional measures addressing political and social realities but moving toward ensuring state interests and control. This approach reflects both Marxist-Leninist theory and imperial Chinese culture. ${ }^{12}$ Even the Hong Kong and Macau Special Adminitrative Regions - which are not minority regimes - have been established as temporary, 50-year measures prior

\footnotetext{
${ }^{11}$ D. Fraser, 'Hollywood can be Inspiration for Tibet, says Dalai Lama, Scottish Example of Devolution is Praised', The Herald, 19 November 2005.

${ }^{12}$ W. Smith, China's Policy on Tibetan Autonomy, East-West Center, Washington, Working Papers No. 2, October 2004, p. 2.
} 
to eventual, full integration. The history of Chinese policy on national minorities has been characterized by pragmatism rather than principle, and current realities and priorities of state control and integration have taken precedence over real autonomy.

\subsection{Policy}

The CCP's understanding of nationality $\left(\right.$ minz $\left.^{13}\right)$ is an adaptation of Stalin's 1913 definition of nationality: a "historically constituted, stable community of people, formed on the basis of a common language, territory, economic life, and psychological make-up manifested in a common culture". ${ }^{14}$

Although the CCP, under the influence of the Comintern in 1931, first accepted Lenin's more radical definition of self-determination for ethnic groups in China and assured a right to independence for minority areas, it retracted this promise by 1935 - as well as notions of federalism based on the Soviet model. The shift away from self-determination and towards autonomy came after the Long March (1934-35) cemented Mao Zedong's status as paramount leader of the Chinese communist movement. ${ }^{15}$ Under Mao, the nationalist and pragmatic orientation of the Party brought in a differentiated approach to the various minority groups located on China's periphery, one based on cooperation with certain groups that had been crucial to ensuring the CCP's survival in difficult years. ${ }^{16}$ Those nationalities who joined the United Front formed by the CCP to fight against the Japanese were to be accorded "the right to handle their own affairs and at the same time to unite with the Hans in building a unified country". ${ }^{17}$ Thus the Chinese government's 2005 White Paper on ethnic issues states, "the patriotic spirit

\footnotetext{
${ }^{13}$ This term is now commonly translated into English in official Chinese documents as "ethnicity" rather than "nationality".

${ }^{14}$ C. Mackerras, China's Ethnic Minorities and Globalisation (2003) p. 2. For a comprehensive analysis of the Chinese ethnic classification system in Yunnan, see T. Mullaney, Coming to Terms with the Nation: Ethnic Classification and Scientific Statecraft in Modern China, 1928-1954, PhD Dissertation, Columbia University, 2006.

${ }^{15}$ For more detail on the CCP's changing policy on self-determination, see Xia, Chunli, 'Reappraising the Right of Self-determination of the People's Republic of China: How Far Can China Go?', in 8:2 Asia-Pacific Journal on Human Rights and the Law 2007.

${ }^{16}$ Most notably with the Hui and the Mongols - but the Tibetans were not in this category, with the exception of a few individuals. J. T. Dreyer, China's Forty Millions: National Minorities and National Integration in the PRC (1979) p. 71. As a reflection of this cooperation, some autonomous areas were set up in areas controlled by the CCP in the early 1940s.

${ }^{17}$ Mao Zedong, CCP Policy on Minority Nationalities (1938), printed in 'Ethnic Compartmentalism and Regional Autonomy in the PRC', XIV Chinese Law and Government (Winter 1981-82) p. 7.
} 
formed during the fight against foreign invasions in modern times is the political basis for practicing regional autonomy for ethnic minorities". ${ }^{18}$

After the founding of the PRC, the Chinese version of NRA was gradually articulated and developed, first in the 1949 Common Programme of the Chinese People's Political Consultative Committee (CPPCC), then the 1952 General Programme for the Implementation of Regional Autonomy for Minorities, and the 1954 Constitution. Many of the key principles in these documents still inform the current system and will be discussed below.

Structuring representation of minorities also involved a scholarly "scientific" dimension, the project of Ethnic Classification (minzu shibie). In a process that began in the early 1950s and was largely completed by $1956,{ }^{19}$ teams of scholars assessed minority groups for designation as officially-recognized nationalities. ${ }^{20}$ While 400 ethnic designations were put forward based on self-identification, only 56 nationalities (including the Han) were eventually recognized.

In the early years of the PRC, the CCP cooperated with local elites, including those in ethnic areas, reflecting the broader "united front" policies, but also its lack of knowledge about, or roots in, most minority areas. ${ }^{21}$ Minority elites were recruited into the new structures of power, and fairly liberal policies on matters such as minority languages were adopted. ${ }^{22}$

The case of Tibet represented the largest degree of accommodation with the existing political leadership in an autonomous area. As a result of negotiations between the Tibetans and Beijing, the "17 Point Agreement" was signed in May 1951. At this point, no detailed outline of the NRA policy had yet been made public. Beijing's principal concession to the Tibetans was the guarantee that the "Central Authorities would not alter the existing political system in Tibet" or the "established status, functions, and powers of the Dalai Lama". As a counter-balance, however, the agreement also recognized a rival religious figure, the Panchen Lama. ${ }^{23}$ The establishment of a Military and Administrative Bureau in Tibet representing the central government was a contentious issue in the negotiations, which the Tibetans only accepted on the

\footnotetext{
${ }^{18}$ State Council of the PRC, White Paper on Regional Autonomy (2005), Section I.2.

${ }^{19}$ K. P. Kaup, Creating the Zhuang: Ethnic Politics in China (2000) p. 88.

${ }^{20}$ Mullaney has demonstrated how Chinese anthropologists adapted the Stalinist classification scheme to fit a consensus among scholars on the basis of ethnicity in China, using language as the primary marker of ethnic distinctions. See Mullaney, supra note 14, pp. 214-215.

${ }^{21}$ See Dreyer, supra note 16, pp. 94 and 102-103.

${ }^{22}$ A. M. Dwyer, The Xinjiang Conflict: Uyghur Identity, Language Policy, and Political Discourse, East-West Center, 2005, p. 7.

${ }^{23}$ In fact, the Tibetan government, as conceived by Beijing, also had a third subdivision: a government formed by secular Tibetans based in Chamdo, eastern Tibet. See Dreyer, supra note 16, p. 134.
} 
understanding that the Bureau would be headed by the Dalai Lama, and that it would be a temporary arrangement. ${ }^{24}$ The agreement reportedly had a "secret codicil" which specified that very few Chinese troops would be stationed in Tibet. ${ }^{25}$ But this agreement was nullified after the 1959 Uprising and was denounced by the Dalai Lama after he fled into exile.

Central Tibet was eventually designated the Tibet Autonomous Region (TAR) in 1965. Other Tibetan regions, Amdo and eastern Kham, had officially been designated nationality autonomous areas - at prefectural and county levels - in the 1950s. This reflected the general preference of the CCP to divide up autonomous areas into several political entities, thus diffusing their political power and securing the principle of central control or democratic centralism. ${ }^{26} \mathrm{~A}$ purpose of this division, which also holds true today, was ensuring security along China's border regions.

The upheaval and radical policies of the Cultural Revolution (1966-1976) saw a negation of autonomy policies as well as extensive cultural destruction and assimilation, particularly in Tibet. In the 1980s, there were attempts to rectify the damage caused by this hard-line, classstruggle approach. In the early 1980s, CCP General Secretary Hu Yaobang visited Tibet and Xinjiang and apologized for the excesses of the Cultural Revolution, ushering in a period of relative liberalism in minority policy. Two CCP documents on Tibet and Xinjiang issued under Hu's leadership reflected a commitment to realizing autonomy, with one even stating that the central government would only retain control over foreign affairs, defence and "veto power". ${ }^{27}$

During the 1980s, various "preferential policies" (youhui zhengce) were introduced for minorities and autonomous areas. On the individual level, these included efforts to train more minority cadres, lower standards for entry of minority students into higher education, and hiring preferences for minorities in certain types of employment in autonomous areas, as well as more

\footnotetext{
${ }^{24}$ M. C. Goldstein, D. Sherap and W. R. Siebenschuh, A Tibetan Revolutionary: The Political Life and Times of Bapa Phüntso Wangye (2004) pp. 150-151.

${ }^{25}$ Ibid., p. 146.

${ }^{26}$ See Smith, supra note 12, p. 11.

${ }^{27}$ See Goldstein, Sherap and Siebenschuh, supra note 24, pp. 287-288. According to Phüntso Wangye, CCP Document No. 31 stated that "under the unified leadership of the central government, Tibet could exercise true autonomy, including the right to make its own decisions. For example, all central government guidelines, policies, instructions, and regulations could be refused or adapted if they did not conform with the practical conditions in Tibet, although for important cases, Tibet would have to ask permission from the central government." Document No. 46 went further: "[I]n special nationality areas like Xinjiang and Tibet, the central government would retain authority over only three areas: foreign relations, national defense, and veto power. All other rights belonged to the minority areas." (The account does not provide dates of these documents).
} 
relaxed controls on family planning. In the autonomous areas, levels of economic investment were raised, and special poverty alleviation measures created. ${ }^{28}$

Reflecting these shifts, the 1982 Constitution contained more extensive provisions on NRA. During the drafting process, the idea that China should adopt a federal system was raised - as it had been during the drafting of the 1954 Constitution - but this was not accepted. ${ }^{29}$ In a departure from the scheme of the 1954 Constitution, however, the 1982 version accorded all local governments at provincial level the power to enact local legislation, among several changes allowing for a greater degree of self-government. In addition, it was agreed that autonomy should be "extensive". ${ }^{30}$ The 1982 Constitution also provided for an additional type of autonomy not based on ethnicity. Article 31 allows for the establishment of "special administrative regions" and was aimed at the "reunification" of Taiwan with the mainland. To date, however, it has been used exclusively to incorporate Hong Kong and Macau into the PRC.

The promulgation of the 1984 Law on Nationality Regional Autonomy (LRNA) implemented the constitutional provisions on autonomy and expanded them in some key areas. The Law was revised in 2001 after many years of discussion.

Following unrest in a number of minority areas - particularly Tibet and Xinjiang - the 1990s saw a tougher approach, abandoning the liberal line of Hu Yaobang to focus on suppressing separatism and fostering economic development as a solution to ethnic unrest. Under this approach, the "autonomy" aspect of the policy has been played down, while "modernization" is seen as the cure for any manifestations of ethno-nationalism. As the 2005 White Paper puts it, "[r] egional autonomy for ethnic minorities enables them to bring into full play their regional advantages and promote exchanges and cooperation between ethnic minority areas and other areas, and consequently quickens the pace of modernization both in the minority areas and the country as a whole and helps achieve common development of all regions and prosperity for all ethnic groups". ${ }^{31}$

Some claim, however, that in recent years central leaders have recognized that the high level of economic subsidies to Tibet and the imposition of state development plans may not only have failed to resolve ethnic tensions but may have actually exacerbated them, thus presenting a

\footnotetext{
${ }^{28}$ Mackerras, supra note 14, p. 27.

${ }^{29}$ Cai Dingjian, The Essence of the Constitution [Xianfa jingjie] (2004) p. 74.

${ }^{30}$ Ibid.

${ }^{31}$ See White Paper on Regional Autonomy, supra note 18, Section I.3.
} 
window of opportunity for the emergence of new policy ideas. Sautman has argued that "[r]ecognition by PRC leaders that Tibet is a conflict like Kosovo, Quebec and Northern Ireland is a sure sign that they feel added pressure to resolve the Tibet Question". ${ }^{32}$

By the late 1990s, the general shift towards marketization of the Chinese economy and the preferential economic policies granted to certain areas, particularly Special Economic Zones, had resulted in enormous disparities in levels of development and living standards between the coastal provinces and the interior. It had also made the economic benefits that had been given to autonomous areas in the 1980s effectively meaningless. As part of its response, in 1999, the Chinese government decided to "upgrade ethnic issues" by improving life in autonomous areas, ${ }^{33}$ and in 2000 it launched a campaign to "Open Up the West." The strategy is essentially to further the integration of the interior provinces, including autonomous areas, with the rest of the country, through increasing Han migration, massive infrastructure projects, and targeted investment. ${ }^{34}$

In sum, although the overall purpose of the NRA policy has changed over time, certain state objectives have remained dominant, including ensuring security along China's borders, an imperative which has informed the approach of integrating autonomous areas and their populations into the PRC. Autonomy has been a pragmatic device for achieving these related goals. Economic development, as defined by the state, has been the principal method adopted in recent years. These purposes are encapsulated in a statement from the White Paper:

\footnotetext{
The implementation of [nationalities regional autonomy] is critical to enhancing the relationship of equality, unity and mutual assistance among different ethnic groups, to upholding national unification, and to accelerating the development of places where regional autonomy is practiced and promoting their progress. ${ }^{35}$
}

\subsection{Legal Framework}

As mentioned above, the legal framework for NRA was first outlined in the Common Programme of 1949, although this provided only the bare bones of the policy. It noted that "regional autonomy shall be exercised in areas where minority nationalities are concentrated"

\footnotetext{
${ }^{32}$ See Sautman, supra note 8, p. 88.

${ }^{33}$ See Mackerras, supra note 14, p. 38.

${ }^{34}$ See, for example, N. Becquelin, 'Staged Development in Xinjiang', 178 The China Quarterly (June 2004).

35 See White Paper on Regional Autonomy, supra note 18, Introduction.
} 
where "various kinds of autonomy organizations" will be established, depending on the relative size of the population and the area in question. ${ }^{36}$ The only specifics provided were that "[a]11 minorities shall have freedom to develop their dialects and languages, to preserve or reform their traditions, customs, and religious beliefs". ${ }^{37}$

The 1952 General Programme for the Implementation of NRA gave a relatively detailed outline of the policy. It stated that all autonomous areas are "an integral part" of the PRC, that their governments are "local governments" led by higher levels and "under the unified leadership of the central people's government". ${ }^{38}$ While the "organs of state power" in autonomous areas would be "autonomous organs", and their governments were to be composed "mainly" of members of the minority or minorities exercising autonomy, the principal forms of rule were prescribed as democratic centralism and the system of people's congresses. ${ }^{39}$ Three different types of autonomous areas could be established where minorities were concentrated: the first was based on a single minority group; the second was an area where one group was dominant in numbers but there were a number of much smaller groups exercising local autonomy; and the third was an area in which two or more groups shared autonomy. ${ }^{40}$ Districts, towns or cities populated by Han people could be included in autonomous areas. ${ }^{41}$

Proposals for the formation of autonomous areas were to be produced through consultation between higher levels of government and minority representatives, but all had to be approved at central level. ${ }^{42}$ Representative conferences were to be convened in the relevant areas, provided "revolutionary order" had been established and "regional autonomy [was] the common desire of all sections of the people". These conferences could be based on existing organizations, or preparatory organizations could be set up for this purpose. ${ }^{43}$

The powers of autonomy described in the General Programme include the ability to determine "the actual form" of the area's autonomous organ and to decide on "internal reforms" ${ }^{, 4}$ based on the wishes of the minorities and their leaders; to adopt the most commonly

\footnotetext{
${ }^{36}$ Common Programme of 1949, Article 51.

${ }^{37}$ Ibid., Article 53.

381952 General Programme for the Implementation of National Regional Autonomy, Article 2.

${ }^{39}$ Ibid., Articles 10, 11, 12.

${ }^{40}$ Ibid., Article 4.

${ }^{41}$ Ibid., Article 5.

${ }^{42}$ Ibid., Article 9.

${ }^{43}$ Ibid., Article 36.

${ }^{44}$ This term implies changes in the social, economic and political system, such as land reform, often initiated by the central government or CCP activists.
} 
used language as "the chief medium of intercourse in the exercise of its authority", and to use this and other minority languages in its culture and education; and "to develop the culture, education, arts, and health services of the various nationalities inhabiting the region". "To give effect to these powers, autonomous areas are given the power to enact special regulations "within the limits of [their] autonomous jurisdiction", but these must comply "with the provisions of the laws and decrees of the central government and the local governments of higher levels", be approved by the two next highest levels of government, and be submitted to the centre for the record. ${ }^{46}$ The General Programme also includes provisions for the exercise of various powers under the "unified" state system, such as finance, economy, and organizing military forces. ${ }^{47}$

As well as mandating equality among the nationalities, the General Programme required that autonomous area governments guarantee to their inhabitants an enumerated list of civil and political rights, ${ }^{48}$ as well as prohibit discrimination and educate people to respect each other's languages, customs, traditions, and religious beliefs. ${ }^{49}$

Higher level governments were exhorted to respect the autonomy powers of autonomous areas and to ensure that their "directives and orders" combine both the "general line of the Common Programme" and "the special characteristics and actual conditions" of these areas. ${ }^{50}$ They were also to assist the autonomous areas in training minority cadres, in "political, economic, cultural, and educational development", and in "overcoming all tendencies to domination by the majority nationality or to narrow nationalism". ${ }^{51}$ A principal method would be to "acquaint the people of the national autonomous regions with the advanced experiences and conditions in political, economic, and cultural development". ${ }^{52}$

By contrast, the provisions of the 1954 Constitution on NRA were more limited. Although most of the elements of the General Programme were included, overall there was a much greater emphasis on the role of the state, as outlined in the final sentence of the preambular paragraph on NRA: "In the course of economic and cultural development, the state will concern itself with the needs of the different nationalities, and, in the matter of socialist transformation,

\footnotetext{
451952 General Programme, supra note 38, Articles 14, 15, 16, 18, 21.

${ }^{46}$ Ibid., Article 23.

${ }^{47}$ Ibid., Articles 19, 20, 22.

${ }^{48}$ Ibid., Article 26.

${ }^{49}$ Ibid., Article 25.

${ }^{50}$ Ibid., Articles 30, 31.

${ }^{51}$ Ibid., Articles 32, 33, 35.

${ }^{52}$ Ibid., Article 34.
} 
pay full attention to the special characteristics in the development of each." The overarching principles were that China is a unitary, multinational state in which all nationalities are equal, and discrimination or acts that undermine "the unity of the nationalities" were prohibited. Nationalities could use their own languages, and "preserve or reform their own customs or ways". Areas inhabited "entirely or largely" by minorities would practice regional autonomy, but such areas were also "inalienable parts" of the PRC. ${ }^{53}$

There was no mention of any role for minorities themselves in defining autonomous areas, and their "organs of self-government" were to be established in the same fashion as ordinary localities, a process prescribed in the Constitution, although "the wishes of the majority" could determine "the form" of these organs. ${ }^{54}$ Requirements for minority leadership were vague, with each nationality only allowed "appropriate representation" in autonomous government. ${ }^{55}$ Higher level state organs were no longer required to "respect" autonomy, but to "safeguard the rights of organs of self-government" and to assist minorities in their development. ${ }^{56}$

The scope of language rights was more constrained. Apart from the provision on being able to use their own language(s) without any context being specified, the only other stipulation was that organs of self-government in the autonomous areas use minority language(s) in "performing their duties". ${ }^{57}$ However, a provision was added requiring courts to use minority languages and provide interpreters. ${ }^{58}$

Limiting the authority of autonomous areas "by law" was a key element. Autonomy needed to be exercised "within the limits of authority prescribed by the Constitution and the law", and autonomous areas were to administer their own finances as "prescribed by law". ${ }^{59}$ During the drafting of the 1954 Constitution, there was debate over whether the autonomous powers of the NRA areas needed to comply with the Constitution and other laws. Leaders such as Deng Xiaoping believed that they should comply. ${ }^{60}$ The Constitution provided for autonomous areas "to enact autonomy regulations and special regulations in accord with the special political,

\footnotetext{
531954 Constitution, Article 3.

${ }^{54}$ Ibid., Article 67.

${ }^{55}$ Ibid., Article 68.

${ }^{56}$ Ibid., Article 72.

${ }^{57}$ Ibid., Article71.

${ }^{58}$ Ibid., Article 77.

${ }^{59} \mathrm{Ibid}$., Article 70. It is unclear which laws they should have been following since the PRC did not enact the LNRA until 30 years later.

${ }^{60}$ See Cai, supra note 29, at 391.
} 
economic and cultural characteristics of the local nationality", ${ }^{61}$ but did not specify any scope for such regulations. However, the approval process for these regulations was made subject to tighter control: all such legislation required National People's Congress (NPC) approval. At the time, no other localities had the power to enact legislation; so this was a significant exception to the PRC's overall unitary scheme. ${ }^{62}$

\section{Current Legal Framework}

The current systems of autonomy were established by the 1982 Constitution - within the broad contours of the nature of the Chinese state. China is defined as a "unitary multinational state" under the command of the Communist Party and the guidance of Marxism-Leninism and Mao Zedong Thought with the aim of furthering socialist policies through democratic centralism and dictatorship. On the nationalities' question, "socialist relations of equality, unity and mutual assistance among the nationalities" will be strengthened. The Constitution also states that autonomy is necessary in order to safeguard the unity of the nationalities and to combat bignation (mainly Han) chauvinism and local national chauvinism. "Han chauvinism" refers to Han arrogance towards and contempt for minorities, rooted in the Confucian perception of minorities as "barbarians". "Local chauvinism" refers to minorities asserting rights claims that go beyond what the central state is willing to countenance. Among the people, particularly the Han, there is as strong a feeling of identity based on ethnicity as on territory. Pye observes that, for "reasons which spring deep from within the Chinese spirit and which have been reinforced during the era of Western encroachment and of the 'unequal treaties', the Han Chinese have developed a powerful sense of their territorial identity, which, some might say, overrides their sense of cultural identity". ${ }^{63}$ Therefore it is within this strong sense of territory and the Leninist obsession with control that autonomy policies and provisions of the 1982 Constitution should be understood and analyzed.

The Constitution recognizes two types of autonomy. The first is regional autonomy for minority nationalities in areas where they "live in concentrated communities" (Article 4). In

\footnotetext{
${ }^{61} 1954$ Constitution, supra note 53, Article 70(4).

${ }^{62}$ This contrast is noted by Zhou Wei, Research on the Legislative Power of Autonomous Areas to Enact Special Regulations[Minzu zizhi difang danxing tiaoli lifaquan yanjiu], Social Science Research, 1998.

${ }^{63}$ L. W. Pye, 'China: Ethnic Minorities and National Security', in N. Glazer and D. P. Moynihan (eds.), Ethnicity: Theory and Experience (1975) p. 488.
} 
these areas, "organs of self-government are established to exercise the power of autonomy." The other system, established under Article 31, gives the NPC broad authority to establish special administrative regions with their own "systems" "in the light of specific conditions". The Constitution provides no further details and hence vests the NPC with much greater flexibility and discretion than for the first type of autonomy. It also envisages, if necessary, a process of negotiations before the constitutional provisions of a special administrative region are established. In this section, we examine the first type of autonomy.

Article 4 sets out China's policy on ethnic ("nationalities") relations. It says that all nationalities are equal, prohibits discrimination against any of them and emphasizes the unity of all nationalities ("any act which undermines the unity of the nationalities or instigates division is prohibited"; "All national autonomous areas are integral part of the People's Republic of China"). It commits the state to assist the economic and cultural development of minority nationalities. It also gives all nationalities the freedom to use and develop their spoken and written languages and to preserve or reform their own "folkways and customs".

The powers of the organs of self-government in autonomous areas are two-fold. Article 115 prescribes that these include "the powers of local organs of state as specified in Section V of Chapter Three of the Constitution" which outlines the powers of non-autonomous units of local government. "At the same time, they exercise the right of autonomy within the limits of their authority as prescribed by the Constitution, the law of regional ethnic autonomy and other laws, and implement the laws and policies of the state in the light of the existing local situation". As mentioned above, areas practicing NRA have these powers as well as those specified as being for ethnic areas only. Arrangements for local government essentially mirror those for the national level, in that local people's congresses (LPCs) are the principal organs of state power at that level (Article 96), with local governments appointed by, and responsible to, them (Article 101). In addition, LPCs at provincial level ${ }^{64}$ have the power to enact local regulations (Article 100). ${ }^{65}$ However, there is a clear tension between accountability of local governments to their respective LPCs and to the higher level state administration; Article 110 lists both responsibilities, and does not indicate how they are to be balanced. But the concluding sentence reflects the reality of governance in the PRC: "Local people's governments ... are state administrative organs under

\footnotetext{
${ }^{64}$ This includes the five autonomous regions and certain cities "directly under the State Council".

${ }^{65}$ These powers are described in detail below in the section on local legislative powers.
} 
the unified leadership of the State Council and are subordinate to it." LPCs at the county (rural) and district (urban) level are directly elected, while the higher level people's congresses are indirectly elected by those below them (Article 97). LPCs are responsible for ensuring that the Constitution, laws and administrative regulations are followed in their jurisdiction, and they also supervise local government policies and budgets (Article 99). As at national level, LPCs meet infrequently (the Organic Law on Local People's Congresses and People's Governments requires meetings "at least once a year" (Article 11)), and much of their day-to-day work is performed by their standing committees, which can exercise most of the powers of the full congresses (Article 104).

The section on local government also provides for directly elected citizens committees to play a substantial role in self-government at the lowest level of administration (Article 111). These residents' committees in urban areas and the villagers' committees in rural areas are not envisaged as government offices. More information on these bodies is provided in the section of this paper on political representation, below.

The general principle of nationalities autonomy is elaborated in Section VI ("The Organs of Self-Government of National Autonomous Areas"). Article 112 prescribes the organs of selfgovernment as people's congresses and people's governments at the regional, prefectural and county levels. If a specified minority exercises autonomy, other minorities in the area should have "appropriate" representation. Members of minorities exercising autonomy should be appointed as chair or vice-chairs of the relevant people's congress (Article 113), while the head of the government of the autonomous unit must be a citizen of the minority exercising autonomy (Article 114). Autonomous areas have the authority to adapt "the laws and policies of the state in the light of the existing local situation" (Article 115).

The powers of people's congresses in autonomous areas include the making of "autonomy regulations and other separate regulations in the light of the political, economic and cultural characteristics of the nationality or nationalities in the areas concerned" (Article 116). However, these regulations require higher level approval. If they are passed by an autonomous region, they have to be submitted to the Standing Committee of the National People's Congress (NPCSC) for approval. If they are passed by lower level congresses, they are submitted to the congress of the province or region (the term "region" is used for provinces which have autonomy) 
for approval; thereafter they are sent to the NPCSC for the "record" ${ }^{66}$ Autonomous areas may administer the finances allocated to them under the state finance system (Article 117) and organize economic development "under the guidance of state plans" (Article 118). They have greater powers to administer educational, scientific, cultural, public health and physical culture affairs, "protect and sift through the cultural heritage of the nationalities and work for a vigorous development of their cultures" (Article 119). They may organize local law and order and security, "in accordance with the approval of the State Council" (Article 120). They may employ local languages "in common use" in the locality for the work of the organs of self-government (Article 121). Finally, the state should help them in economic and cultural development and in training a "large number" of cadres and specialized personnel and skilled workers of various professions and trades (Article 122) and take due account of local interests when "exploiting natural resources and building enterprises in the national autonomous areas" (Article 118).

The Constitution also provides for the representation of minorities at the national level; they must be represented at the "appropriate level" in the NPC and NPCSC (Articles 59 and 65).

As mentioned above, a second type of autonomy under the Chinese constitution is provided under Article 31. It was established in the 1982 Constitution and seeks to overcome some of the limitations of NRA. The Article is short and there is little else in the Constitution which relates to this type of autonomy. The Article itself tells us very little about the purposes and nature of the autonomy. It reads:

The state may establish special administrative regions when necessary. The systems to be institutionalised in special administrative regions shall be prescribed by law enacted by the National People's Congress in the light of specific conditions.

Thus the NPC is given maximum flexibility to formulate the scope and contours of autonomy and adapt it to the circumstances of a region. The autonomy must be established through a law enacted by the NPC, and as a basic law, it would enjoy a higher status than ordinary law. ${ }^{67}$ The reference to "systems" to be instituted suggests that the region may be granted characteristics and

\footnotetext{
${ }^{66}$ This wording may suggest that the NPCSC has no further responsibility, but it has a general power to annul local regulations "that contravene the Constitution, the law or the administrative rules and regulations", Article 67(8).

${ }^{67}$ This scenario is based on how this article was used in establishing the Hong Kong and Macao Special Administrative Regions .
} 
the power to make policies different from those of the mainstream system, reminiscent of the content of NRA in the early 1950s and the 17-Point Agreement. It has become customary to refer to the autonomy under Article 31 as "one country, two systems", but these words are not used in the Constitution. It is well known that an arrangement under which Taiwan would rejoin China but retain its market economy, political system and even its army was envisaged. It has so far been used as the foundation for the transfer of sovereignty of Hong Kong and Macau.

As under Chinese law, the Constitution is not binding by itself (see below); the effective regime of minority autonomy is to be found in the LRNA which was passed in 1984 and significantly amended in 2001. The Law repeats many provisions of the Constitution on the context and parameters of autonomy. These include: (a) autonomy exists within the framework of a unitary state; (b) which itself, along with autonomous areas, is bound by the supremacy of the Chinese Communist Party and governed by the "democratic dictatorship" of the people; (c) autonomy powers are to be exercised under "unified state leadership" (explicated by a number of provisions); (d) autonomous areas' highest responsibility is to promote and uphold national unity and to "place the interests of the state as a whole above anything else and make positive efforts to fulfil the tasks assigned by the state organs at higher level" (Article 7); (e) where Han people are a minority, they are entitled to the rights of a minority (Article 12); (f) most powers granted to autonomous areas are to be exercised in accordance with "legal stipulations" or the "law"; and (g) autonomy has to fit within the hierarchy of authority whereby state organs direct, control and supervise the exercise of general and autonomous powers at the local levels.

The 2001 amendments introduced another critical factor: market oriented economic development, in accordance with China's commitment to rapid economic development (see Chapter V). The Law reserves all the major economic powers and the use of economic instruments for the state. It commits autonomous areas, as other parts of the country, to the modernization of the economy (and implicitly to new relations of production). They now have to follow policies of encouraging domestic and foreign investment, promote the mobility of labour and skills, adopt high technology, undertake massive programmes of education and training in technology and management, increase economic production and exports, and build infrastructure. These activities have to be conducted in accordance with state direction and assistance, and conform to state plans. The state is expected to use financial, monetary, and technological instruments to speed up economic development in autonomous areas. Special incentives will be 
provided for the exploitation of natural resources and basic infrastructure. The state would assist to bring in skilled labour from the more developed areas (presumably from predominantly Han areas), and organize training for local people through instruction in institutions outside the autonomous areas and establishing educational institutions in the autonomous areas. The general thrust of this Chapter of the Law is the greater integration of autonomous areas into the economy and administration of the country under the direction of central authorities. Autonomous areas are offered little space for their own policies, and the Chapter is more in the nature of mandatory provisions, incompatible with the concept of autonomy. Privileging of economic development over other goals shows that there is no deep commitment to the culture of nationalities.

One important positive change made in the 2001 LNRA revisions was that time-limits were set for the centre to respond to requests for policy waivers (Article 20). Prior to this, the centre could effectively veto such requests by failing to respond.

In sum, the following propositions about the extent of minority autonomy arise from the language and context of the autonomy provisions in the Constitution and LNRA:

- The primary purpose of autonomy is to strengthen national unity by bringing minority nationalities within the state system. Political arrangements in autonomous areas are vehicles for the enforcement of national laws and policies.

- Autonomy is decided on and imposed by the central authorities rather than negotiated to reflect the interests of national minorities.

- There is considerable emphasis on local culture and language, but culture seems to be understood in a somewhat restrictive way ("folkways and customs"). As we shall see there is little freedom of religion, which for many communities is an essential part, and sometimes the underlying basis, of culture.

- Despite provisions in the Constitution, there is no entrenchment of autonomy; it is based on ordinary law which can be changed at the will of the NPC or even the NPCSC.

- There is no entitlement to autonomy. Article 12 of the Law says that "[a]utonomous areas may be established where one or more minority nationalities live in concentrated communities, in the light of local conditions such as the relationship among the various nationalities and the level of economic development, and with due consideration for historical background". These subjective criteria are linked to the concept of nationality, which as mentioned above was based on the Stalinist conception. Even if a group has 
been accepted as a nationality, the decision to establish an autonomous area is made, in the case of an autonomous region, by the NPC (Constitution Article 62(2)), and in the case of autonomous prefectures and counties, by the State Council (Constitution Article $89(15))$.

- A massive influx of people from other communities could upset any expectation of autonomy, diluting the special status of the dominant minority. This has become a particular problem with the movement of Han people into minority areas.

- Autonomous areas fit within the hierarchy of institutions of state, and are subordinated to institutions at the next higher level. Their powers must be exercised within the laws, regulations and directions of central authorities, with limited possibilities to opt out of them or take initiatives of their own (see below).

- There is no area in which the central authorities cannot invade the autonomy of a nationality. It should be emphasized that NRA does not specify spheres of powers or subject matter, such as culture, in which the central authorities cannot intervene.

- Autonomous areas must fit within the general framework governing local institutions generally. They have no authority to determine the structure or democratization of their institutions or modes of representation. Coupled with a lack of effective protections of the freedoms of religion, expression, association and assembly there is a significant deficit of self-government.

- There is no independent institution to adjudicate conflicts between central and autonomous authorities on the scope or violations of autonomy.

- Although a considerable role is prescribed for members of the dominant and not so dominant minorities in the local people's congresses and governments, nothing is said about the organization of the institutions of the Chinese Communist Party with whom real power lies (see below for the role of the $\mathrm{CCP}$ ).

These limits are reinforced by Chinese government pronouncements on the purpose and scope of autonomy set out in its periodic White Papers. These essentially reiterate the framework outlined 
above, and present an optimistic picture of how NRA functions in practice, focusing, for example, on minority representation in the local people's congresses. ${ }^{68}$

\subsection{Scholarly Assessment of NRA}

Many scholars, including some within China, have been critical of the NRA system. For example, Yu's assessment of the legal and institutional framework for NRA concludes that "[i]t is fair to say that the autonomy granted by the PRC Constitution and Ethnic Regional Autonomy Law to the autonomous areas is limited administrative autonomy". 69 Potter writes that the Constitution justifies "state-centric governance and gradual diminution of local ethnic identity" and serves "to entrench policy ideals and approaches that have the potential to marginalize minority nationalities". 70

A number of scholars have concentrated on how the CCP's development strategies have served to exacerbate ethnic tensions, in particular by increasing economic disparities between border regions and more developed areas. Sautman argues that the LRNA "does not mandate the creation of minority economic opportunities sufficient to overcome the gap ..." ${ }^{71}$ He also cites Zhang Huijun's claim that "the gap creates an 'ethnic psychological imbalance' ... that can emerge as an unfavorable factor for unity and stability". ${ }^{72}$ The effort to redress such imbalances through the Western Development Strategy is viewed by many as problematic since its effects in

\footnotetext{
${ }^{68}$ These include the White Paper on Regional Autonomy, supra note 18, and another White Paper on Regional Ethnic Autonomy in Tibet published by the State Nationalities Affairs Commission in May 2004. The 2004 White Paper presents a rosy view of what has been achieved in the TAR: "Since regional ethnic autonomy was implemented in 1965 in Tibet, the Tibetan people, in the capacity of masters of the nation and under the leadership of the Central Government, have actively participated in administration of the state and local affairs, fully exercised the rights of self-government bestowed by the Constitution and law, engaged in Tibet's modernization drive, enabled Tibetan society to develop by leaps and bounds, profoundly changed the old situation of poverty and backwardness in Tibet, and greatly enhanced the level of their own material, cultural and political life."

${ }^{69} \mathrm{Yu}$ Xingzhong, Ethnic Regional Autonomy in the People's Republic of China, International Conference on Comparative National Experiences of Autonomy: Purposes, Structures and Institutions, Centre for Comparative and Public Law, The University of Hong Kong, 10 April 2005, p. 14 (emphasis added).

${ }_{71}^{70}$ Potter, supra note 6, p. 305.

${ }_{71}^{71}$ B. Sautman, 'Ethnic Law and Minority Rights in China', 21 Law and Policy (1999) p. 285.

${ }^{72}$ Zhang Huijun, 'A Probing of the Gap in the Economic Development of the Minority Areas' [Minzu Dichu Jingji Fazhan Chaju De Tanxue], 4 Yunnan Social Science [Yunnan Shehui Kexue] (1996) p. 33, cited in ibid. at p. 285
} 
minority regions will likely include greater integration of ethnic minority areas into the Han political and economic system. ${ }^{73}$

Zhou asserts that the "institutional design" of NRA means that it cannot achieve its stated objectives. In particular, the mere presence of minority officials in autonomous areas' governments is insufficient for the realization of minority rights. He points out that there are no mechanisms in the PRC's NRA system that allow for the articulation and representation of the interests of minorities. ${ }^{74}$ Other commentators have pointed to the reluctance of governmental departments at provincial or state level to devolve powers relating to economic interests to autonomous areas and attribute the absence of any autonomous regulations at the level of national autonomous regions to such attitudes. ${ }^{75}$ Zhou and Lundberg demonstrate through a study of the regulation of hunting in the Oroquen Autonomous Banner that state officials lacked sensitivity to the concerns and wishes of the people to preserve their culture (where "the hunting life style is the primary marker of their ethnic identity"). Instead they were preoccupied with historic leaps in economic development, and banned hunting to force people to lead a sedentary life style and engage in economic pursuits which fit into mainstream ideas of proper economic activities, thus undermining their traditional practices. ${ }^{76}$

It is clear both from the law and practice that the concept of "autonomy" in China is fundamentally different from increasingly accepted understandings of autonomy standards. ${ }^{77}$ In the latter sense, autonomy is a device to allow ethnic, religious, linguistic or cultural communities claiming a distinct identity, whether aggregated geographically or not, to exercise direct control over affairs of special interest or concern to them, while allowing the larger entity those powers which cover common interests. The precise forms and structures of autonomy

\footnotetext{
${ }^{73}$ See generally Becquelin, supra note 34; Potter, supra note 6, pp. 314-317; and M. D. Moneyhon, 'China's Great Western Development Project in Xinjiang: Economic Palliative or Political Trojan Horse?', 31 Denver Journal of International Law and Policy (Summer 2003).

${ }^{74}$ Zhou Yong, Political Principles vs. Legal Techniques: Group Rights Perspective on Combining 'Regional' and 'National' Autonomy in China (2005, unpublished paper on file with the authors).

${ }^{75}$ Zhu Guobin and Yu Lingyun, 'Regional Minority Autonomy in the PRC: A Preliminary Appraisal from a Historical Perspective', 7 International Journal on Minority and Group Rights (2000) pp. 54-55.

${ }^{76}$ Zhou Yong and M. Lundberg, Hunting Ban against the Last Hunting People in their Autonomous Area: Three Key Issues for the Implementation of China's Regional National Autonomous Law in Oroqen Autonomous Banner (2005, unpublished paper on file with the authors) p. 2.

${ }^{77}$ Y. P. Ghai, 'Ethnicity and Autonomy: A Framework for Analysis', in Y. P. Ghai (ed.), Autonomy and Ethnicity: Negotiating Competing Claims in Multi-Ethnic States (2000) p. 2.
} 
differ from country to country (and in particular forms suitable for territorial autonomy are necessarily different from group autonomy). But the following features are generally relevant: ${ }^{78}$

- Autonomy arrangements which are negotiated in a democratic and participatory way are more likely to succeed than those which are imposed.

- There is a clear division of powers between the central and autonomous authorities (even if there are areas of concurrent powers).

- Institutions at the autonomous level must be representative of the autonomous community (to give moral and political strength to autonomous governments).

- The broader, national system must also be democratic and pluralist.

- The autonomous area must have adequate financial resources and administrative capacity.

- Autonomy arrangements must be legally guaranteed and constitutionally entrenched, not liable to be changed by the unilateral decision of central authorities.

- There must be some mechanism for consultations between autonomous and central authorities on matters of common interest and to resolve disputes.

- There must be an independent institution (preferably an independent court) to adjudicate disputes between the autonomous and central authorities if a negotiated settlement is not possible and to interpret constitutional provisions.

At the moment these conditions do not apply in China. The PRC still looks at the role of a constitution with Leninist spectacles: as an imposition, recording the victory and securing the dominance of the Communist Party, a statement of Marxist ideology and "democratic" centralism, imposing no obligations on rulers but constraining the ruled. There are no genuinely independent institutions (and this includes the judiciary). Statements of human rights do not translate into guarantees. The Constitution is not directly enforceable. These are not promising circumstances for genuine autonomy. However, as we show later, there are some signs of moves towards pluralism and democratization that might lend support to the recognition of some prerequisites for autonomy.

\subsection{Is Article 31 Applicable to Tibet?}

${ }^{78}$ Ibid. 
As mentioned above, one way of addressing the deficit of autonomy in NRA and advancing a more genuine version for Tibet would be a Hong Kong-style solution. In what ways may Article 31 autonomy be superior to NRA? If applied to Tibet, what problems might it solve that are inherent in NRA? How easily can Article 31 autonomy be applied to Tibet given that it has been integrated into the economic and legal system of the Mainland? We examine these questions through a brief examination of the experience of Hong Kong. However, it should be pointed out that a hallmark of Article 31 is its flexibility; the Hong Kong SAR does not need to serve as a prototype (although it seems to have done so for Macau), ${ }^{79}$ and the scope and mechanisms of autonomy would undoubtedly be different if eventually applied to Taiwan as originally envisaged.

A major barrier to such a solution is the PRC's insistence that Article 31 cannot apply to Tibet. The 2004 White Paper on Tibet states that:

The situation in Tibet is entirely different from that in Hong Kong and Macau. The Hong Kong and Macau issue was a product of imperialist aggression against China; it was an issue of China's resumption of exercise of its sovereignty ... the Central government has always exercised effective sovereign jurisdiction over the region.

The PRC position is that Article 31 may only be used for the recovery of regions which were taken away from the "motherland" and cannot therefore be applied in Tibet. But it is hard to sustain the idea that Article 31 was envisaged as having any broader application than as a solution to the Taiwan question. The provision is clearly linked to the preambular statement: "Taiwan is part of the sacred territory of the PRC. It is the lofty duty of the entire Chinese people, including our compatriots in Taiwan, to accomplish the great task of reunifying the motherland." ${ }^{\prime 80}$

Cai describes Article 31 as being specifically designed to incorporate into the PRC distinct areas of the country "where, for historical reasons, socialism had not been practiced" and allow them to continue their existing systems, capitalism in particular. ${ }^{81}$ A report from the time

\footnotetext{
${ }^{79}$ Y. P. Ghai, 'The Basic Law of the Special Administrative Region of Macau: Some Reflections', 49 International and Comparative Law Quarterly p. 183 (January 2000).

${ }^{80} 1982$ Constitution, preamble, para. 9.

${ }^{81}$ Cai, supra note 29, p. 202.
} 
cites an NPC deputy as stating that the autonomy of SARs differs from national and ordinary local autonomy. ${ }^{82}$ However, the provisions in both the 1951 17-Point Agreement between Tibet and the Central People's Government and the General Programme on the accommodation of different "systems" can be regarded as the precursors of Article 31 and thus the question of its application in Tibet may be raised. Also, the very fact that the NRA system incorporates autonomous areas at different administrative levels with varying powers indicates that autonomy in the PRC has consistently been asymmetrical, and that a differentiated approach has been taken in which the circumstances of each autonomous area is considered on its own.

Hong Kong became the Special Administrative Region of Hong Kong of the People's Republic of China (HKSAR) on 1 July 1997 when Britain transferred sovereignty over Hong Kong to China. There were two distinct phases in the establishment of the HKSAR. The first was negotiations between China and Britain on the terms of the transfer of sovereignty. ${ }^{83}$ At first China was reluctant to negotiate the terms with Britain; instead it stated "one country two systems" as the basis of Hong Kong's constitutional system. Under it Hong Kong's economic, legal and social systems, including the protection of human rights, would remain unchanged, and its political system would retain its essential features (including the absence of democracy) but adjusted to the reality of a new "sovereign". All of this was encapsulated in about 12 points on one page. However, Britain wanted a treaty to agree on Hong Kong's new system, and was concerned to elaborate the provisions of the new law for Hong Kong in great detail and to secure firm legal foundations. The result was the Sino-British Joint Declaration on the Question of Hong Kong, 1984, which would also serve as the basis of the Basic Law that the NPC would enact.

The second phase was the drafting of the Basic Law by a Basic Law Drafting Committee appointed by China. It consisted of 59 members, of which a majority (36) were from the Mainland. The drafting of the Law, which was intended to give effect to the Joint Declaration, took about four years. It was enacted in April 1990 and came into effect on 1 July 1997.

This brief account indicates that Article 31 could serve as a framework for negotiations, unlike the NRA law which is detailed, non-negotiable and cannot really be accommodated to the specific needs of a region. But the PRC position sometimes has been that the Central Authorities

\footnotetext{
${ }^{82}$ Xinhua, 29 November 1982.

${ }^{83}$ Ghai, supra note 5.
} 
would not negotiate with its own people, and the Article became the framework for negotiations only because sovereignty rested with a foreign power. However, the PRC cannot be too dogmatic about it because in the case of Taiwan, it would have to negotiate with its people and leaders.

The second point is the flexibility that the Article facilitates. Under the Basic Law, Hong Kong was enabled to opt out of many provisions of the Chinese Constitution, in particular the detailed way in which the rule of the Communist Party is expressed (including the nomenklatura), and Marxist political and economic ideology. Very few Mainland laws apply in Hong Kong. The Hong Kong legislature has the authority to make laws and policies on all matters other than defence and foreign affairs, but even in these areas, it has primary responsibility for internal security and is authorized to enter into agreements with foreign states and international organisations (and is a member of many international and regional organizations). Hong Kong has its own currency, monetary and fiscal system; can issue its own passports; controls its immigration policies; decides on infrastructural development; is responsible for education, health, etc. It has its own system of justice, the common law applies, and there is a separate - and independent - court system. English is an official language. Land belongs to the state, but its administration is in the hands of the SAR (income from sale or lease of lands goes to Hong Kong). Rights and obligations are based more on the concept of a "permanent resident of Hong Kong" than on Chinese citizenship, which enables Hong Kong to preserve its identity and restrict entry to and residence in Hong Kong of Mainlanders (and others).

The third point is that it has been possible to secure relatively secure legal foundations for Hong Kong's autonomy - based on an international treaty with Britain (which is no longer of any great practical significance) and national constitutional provisions. The NPC can amend the Basic Law, but no amendment can "contravene the established basic policies of the PRC regarding Hong Kong" ${ }^{\Perp 4}$ - a reference to the provisions of the Joint Declaration. Within Hong Kong, the Basic Law - which entrenches fundamental human rights - is supreme and all other Hong Kong laws must be compatible with it. An independent judiciary reviews challenges to laws, regulations and policies, thereby reinforcing the special status of the Basic Law, and preserving the rule of law to a greater extent than any other region of China.

This is not to say that problems do not exist. Although the Basic Law defines in detail the relationship between Hong Kong and Mainland institutions, with a view to ensuring Hong

\footnotetext{
${ }^{84} 1997$ Basic Law of the Hong Kong Special Administrative Region, Article 159.
} 
Kong's autonomy, it has been hard in practice to fully ensure that autonomy. The Central Authorities are frequently referred to as the "sovereign"; the Chief Executive of Hong Kong is essentially an appointee of the Central People's Government, and being the most important official in Hong Kong, serves to implement directives s/he receives from Beijing. The lack of democracy in political institutions in Hong Kong and China means that decisions are made bureaucratically, without people's participation, and the autonomy of the people is thereby weakened. Doubts remain as to the exact scope of the application of the PRC Constitution (contrary perhaps to the intention that the Law under Article 31 would establish a self-standing constitutional order). The Standing Committee of the NPC has the power to interpret the Basic Law and thus bypass the restrictions on its amendment in Article 159. This power has been used three times and has arguably undermined the legal foundations for Hong Kong's autonomy. ${ }^{85}$ There is no independent judicial body which can adjudicate disputes over the provisions regarding the relationship of Hong Kong and the Central Authorities. These matters are in fact decided by the Central Authorities themselves. The constitutional foundations of Article 31 autonomy have turned out to be less effective than was once expected. The autonomy is granted for only 50 years, and since the Basic Law came into force, there has been greater economic and social integration between Hong Kong and China than was implicit in that Law. On the positive side, apart from differences over democracy, there has been little to divide Hong Kong and China, and in practical, day-to-day matters, Hong Kong enjoys considerable autonomy, and is able to pursue its distinctive lifestyle.

So Article 31 autonomy, suitably framed, would be in Tibet's interests. Tibet may not need the same degree of autonomy, e.g. of monetary or fiscal systems, international trade or the legal system, but the freedom of religion, freedom to pursue language policies, and develop a distinct political system based on genuine local representation and participation, and relations between Tibetans and non-Tibetans living in Tibet, necessary to the vision Tibetans have of their region, could be accommodated under Article 31.

Whether Tibet would be entitled to rely on Article 31 is more a political than a legal issue. Even in the disputed 17-Point Agreement, Tibet's special status and its distinctive concerns are

\footnotetext{
${ }^{85}$ The Standing Committee of the National People's Congress has exercised this power three times since 1997: 1) in June 1999, in relation to the right of abode of mainland-born children of Hong Kong residents; 2) in April 2004 in relation to Hong Kong's political and democratic development; and 3) in April 2005 in relation to the Chief Executive's term of office.
} 
recognized, which prompted a separate treatment of Tibetan from other minorities. In addition, it seems evident that the idea of tolerating "different systems" within the PRC that is expressed in Article 31 originated in NRA as conceived in the years immediately after 1949. It is clear that the needs and legitimate aspirations of Tibetans are distinctive in several respects, and if genuine autonomy is to be exercised in Tibet, the framework of the NRA as it has operated in the reform era will be inadequate. At the least, considerable adjustments to the NRA legislation would be necessary, and a midway position between NRA and Article 31 may be required.

\section{The Operation of National Minority Autonomy}

\subsection{Political Representation and the Role of the Chinese Communist Party}

Although the extent to which China is democratizing is hotly debated among scholars and observers, it is indisputable that mechanisms to make local governance more accountable are providing opportunities for some popular input into local politics. These mechanisms could potentially allow for the engagement of a wider range of Tibetan interests in local political affairs, particularly if it were in a climate of reduced tensions in the TAR and other Tibetan areas. Also, if there were more involvement of independent-minded Tibetans in the local people's congresses (LPCs), this could make for a more effective and meaningful use of the legislative powers granted to the TAR and to other Tibetan autonomous areas (described below).

However, the growing Han presence in the cities of the TAR may militate against the impact of greater representation. The PRC has institutionalized discrimination against rural residents in its people's congress system, with one urban vote having the same weight as four rural votes. Since Tibetans in the TAR mostly live in rural areas, they will have fewer deputies representing them than urbanites, thus giving the votes of Han settlers greater weight. By the early 1990s, Han representatives made up a majority in three of the five autonomous regions in the PRC. ${ }^{86}$

The dominance of the CCP in the Chinese political system is another factor that effectively limits the functioning of the autonomy system, and blocks the formation of

\footnotetext{
${ }^{86}$ Chien-min Chao, 'The Procedure for Local Legislation in Mainland China and Legislation in National Autonomous Areas', Issues and Studies (September 1994) pp. 106-107.
} 
institutions that are genuinely representative of minority interests. Political considerations are paramount in the implementation of regional ethnic autonomy. Party policies toward ethnic minorities (and Tibetans in particular) need to be considered along with the legal framework.

This section briefly reviews developments in electoral politics in the reform-era PRC that could provide greater representation, and then proceeds to consider the impact of the CCP's organizational grip on the possibilities for greater exercise of autonomy in the TAR.

\subsubsection{The Electoral System}

The spread of competitive elections to villagers' committees in China's countryside has elicited a great deal of speculation about the CCP's attitude to democratisation. While these elections are certainly significant, it is important to point out that apart from this and some minor local experimentation, the electoral system has remained basically unchanged since the enactment of the 1979 Election Law. ${ }^{87}$

Control over nominations has been the major means by which the CCP has continued to dominate the electoral process. Although the 1979 Election Law provided for secret ballots, expanded the scope of direct elections to PCs at county/district level, required more candidates than seats and allowed any three voters to nominate a candidate, in practice Party-dominated election committees ${ }^{88}$ have continued to ensure that the candidate list reflects the CCP's wishes. The Election Law does not stipulate a procedure for producing a formal list of candidates from those nominated. ${ }^{89}$

Discrimination against rural people is reflected in the electoral system, in which rural votes count much less than those in urban areas. The 1979 Election Law, as amended in 1995, ${ }^{90}$ provides that a universal proportion of four rural votes is equivalent to one urban vote. ${ }^{91}$ In the Tibetan areas this requirement would mean that votes of the Han population officially resident in the cities have greater weight than those of rural Tibetans.

\footnotetext{
${ }^{87}$ For an analysis of how the electoral system works in autonomous areas, see Xia, Chunli, 'To be the Masters of Their Own Affairs: Minorities' Representation in Regional Ethnic Autonomy of the People's Republic of China', in 8:1 Asia-Pacific Journal on Human Rights and the Law 2007.

${ }^{88}$ Generally the chairman of the election committee is the Party secretary of the Party organization at the same level.

${ }^{89}$ Lin Feng, Constitutional Law in China (Hong Kong: Sweet and Maxwell Asia, 2000), at 186.

901979 Election Law, Article 4 of amendments.

${ }^{91}$ Lin, supra note 89, pp. 174-175.
} 
Promoting mechanisms to make officials accountable has been one aspect of Beijing's project of ensuring political stability. The idea that the attitude of the people towards candidates for leadership should matter under the "principle of recognition by the masses" has been one aspect of this. ${ }^{92}$ This takes a variety of forms, including primary elections under the name of "opinion polling."

One example of this emerged from Shanxi Province in the 1990s, where protests against corrupt and abusive village Party leaders led to a system of subjecting candidates for office in village Party branches to a "vote of confidence" or "vote of recommendation" prior to the formal intra-Party elections for these posts. Such practices have now spread to a number of provinces, despite lack of endorsement by the centre. ${ }^{93}$ In some places, the CCP has conducted opinion polls to determine attitudes towards different candidates for local Party leadership positions. ${ }^{94}$

\subsubsection{The Role of People's Congresses}

A noted development in Chinese politics over the last two decades has been the rise of the people's congresses (PCs) as an important power base at the national and the local level. This does not mean they have become independent; they are still dominated by the Party, with about 70 per cent of PC deputies nationwide being CCP members. ${ }^{95}$ However, a handful of independent deputies have been elected to local people's congresses (LPCs) nationwide.

As institutions the PCs are playing a growing role in the political system, both as the source of the legislation which codifies the constitutional provision "ruling the country in accordance with law and establishing a socialist rule of law state" 96 and as a mechanism of "supervision" over government.

LPCs have often been pioneers in establishing mechanisms for holding government agencies accountable. One major way in which they do this is through supervising the implementation of law. This function first appeared in the mid-1980s when PCs initiated law

\footnotetext{
${ }^{92}$ Li Lianjiang, 'The Two-Ballot System in Shanxi Province: Subjecting Village Party Secretaries to a Popular Vote', 42 The China Journal (1999) p. 108.

${ }^{93}$ J. P. Horsley, 'Village Elections: Training Ground for Democratization', 28 The China Business Review (2001).

${ }^{94} \mathrm{Li}$, supra note 92 , pp. 103-109.

${ }^{95}$ Zou Keyuan, 'Harmonizing Local Laws with the Central Legislation', 52 China Perspectives (March/April 2004) p. 47.

${ }_{96}$ This was added as an amendment to the Constitution in 1999.
} 
implementation inspection visits. Whether in the NPC or in LPCs, special panels are set up for the purpose, which sometimes solicit opinions from the public and publicize inspection activities and their outcomes through the media. ${ }^{97}$

\subsubsection{Village Elections}

The aspect of political reform in the PRC that has attracted the greatest attention overseas is elections to villagers' committees (VCs). Often dubbed "grassroots democracy", the spread of competitive and relatively open elections to many villagers across the country has been heralded as the first step towards democratization in China.

VCs (and urban residents' committees) were written into the 1982 Constitution as elected "mass organisations of self-management at the grassroots level." Their tasks are: "The residents' and villagers' committees establish committees for people's mediation, public security, public health and other matters in order to manage public affairs and social services in their areas, mediate civil disputes, help maintain public order and convey residents' opinions and demands and make suggestions to the people's government" (Article 111).

Villagers committees are not technically organizations of government, but a kind of executive of village self-governance. As Thurston puts it, "[e]lected village leaders are not government officials. Rather, they are transmission belts between the government and the villagers, reporting popular opinion and proposals to the government, helping to maintain social order, and mediating civil disputes." ${ }^{.98} \mathrm{VCs}$ are also responsible for implementing state policies in the villages.

After more than a decade of experimentation with competitive village elections, in November 1998 the NPCSC passed the Organic Law of the Villagers' Committees of the PRC. The Organic Law includes various provisions related to elections, such as banning appointment of members to VCs (Article 11), requiring the publication of an electoral roll 20 days before polling (Article 12), requiring the establishment of an election committee elected by the

\footnotetext{
${ }^{97}$ Cai Dingjian, 'Functions of the People's Congress in the Process of Implementation of Law', in Chen Jianfu et. al. (eds.), Implementation of Law in the People's Republic of China (2002) pp. 41-45; and Chao Chien-min, 'The National People's Congress Oversight: Power and the Role of the CCP', in K. E. Brodsgaard and Zheng Yongnian (eds.), Bringing the Party Back in: How China is Governed (2004) pp. 129-131.

${ }^{98}$ A. F. Thurston, Muddling Towards Democracy: Political Change in Grassroots China, US Institute of Peace, 1998, p. iii.
} 
Villagers' Assembly ${ }^{99}$ (Article 13), requiring a greater number of candidates than seats ${ }^{100}$ and candidates to be nominated by members of the electorate, and mandating secret ballots and open vote counting (Article 14). In some areas, nomination procedures have been made more open and meaningful by conducting primaries, in which all voters can nominate candidates for available offices. This often leads to a situation in which there are many more candidates than seats, with two or more contesting each top position. ${ }^{101}$

The 1998 law also incorporated a new article on CCP basic level organizations acting as the "leadership core" in the villages that, "in accordance with the Constitution and the laws, support and guarantee that villagers engage in self-governance activities and directly exercise their democratic rights" (Article 3). The continuing lack of clarity about the relationship between these two institutions often results in tensions. ${ }^{102}$

The proportion of villages which have held competitive elections for VCs is unclear. Even where contested elections have been held, the impact on local conditions and power structures vary enormously, particularly given the dual authority structure of Party and government. Economic factors such as the degree of industrialization and the linkage of the village economy to the outside, including by migration, are crucial in determining the locus and nature of decision-making in any particular village, and the level of interest of villagers in elections.

\subsubsection{Elections to Urban Residents' Committees}

In recent years, there have been some experiments with contested election of urban residents' committee (RC) members. Although RCs are included in Article 111 of the 1982 Constitution and the Organic Law of the Urban Residents' Committees of the PRC passed in December 1989

\footnotetext{
${ }^{99}$ This is supposed to be composed of all adult villagers or their representatives.

${ }^{100}$ It is important to note that the Chinese term often translated as "competitive elections" (cha'e xuanju) just means that there should be more candidates than seats available, not that there should be competition for each post. Thus there may be four candidates for three available posts, as Manion observed in elections to township congresses in the Chongqing Municipality. See M. Manion, 'Chinese Democratization in Perspective: Electorates and Selectorates at the Township Level', 163 The China Quarterly (2000) pp. 767-769. Pastor and Tan write that in "most" of the VC elections they observed there was only one more candidate than seats available. See R. A. Pastor and Tan Qingshan, 'The Meaning of China's Village Elections', 162 The China Quarterly (2000) p. 507.

${ }^{101}$ See Horsley, supra note 93.

102 J. C. Oi and S. Rozelle, 'Elections and Power: The Locus of Decision-Making in Chinese Villages', 162 The China Quarterly (2000) p. 522.
} 
(coming into effect on 1 January 1990) is very similar to the Organic Law on VCs, the functioning of RCs has generally received much less attention. In 1999, the Ministry of Civil Affairs launched experiments in 20 cities on "fresh approaches to urban grassroots selfgovernance" including contested elections to RCs. Often the procedures used have been those developed for $\mathrm{VC}$ elections.

According to the law, RCs cover 100-700 urban households, are supposed to be composed of elected members, and answer to a residents' assembly. In practice, however, RC members have generally been appointed by local government and Party organs. RC members depend on stipends provided by local governments, and their only potential resource base is businesses they run or fee-paying services they provide. Along with their notorious monitoring function, they are also responsible for local security, dispute mediation, birth control and public health, environment and sanitation, legal education and social services. ${ }^{103}$

\subsubsection{What Role for the Party in Elected Bodies?}

As mentioned above, the relationship between the Party and institutions composed of elected representatives, such as VCs, has sometimes been tense, due in part to a lack of clarity about the extent to which VCs are subordinate to Party branches. Party policy clearly indicates that the leadership role should belong to the CCP, however, since it is "the faithful representative of the interests of the people of all nationalities, acting as the core that brings together the efforts of the people of all nationalities". ${ }^{104}$ Of course Party dominance is also written into the Constitution, and appears as one of the principles in the LNRA. While this is in part an indication of the status of the Law as a constitutional law, it also emphasizes the importance of the CCP's role in the practice of NRA.

The CCP's actual exercise of power is based primarily on its organizational capacity. In this respect, it remains a Leninist institution, in which lower level institutions and members are strictly subordinated to higher levels. A key principle in the Party's internal organization and mode of exercising governance is democratic centralism. This means that while input into policy

${ }^{103}$ A. C. Choate, Local Governance in China, Part II: An Assessment of Urban Residents Committees and Municipal Community Development, The Asia Foundation, Working Paper No. 10 (1998) pp. 16-25.

${ }^{104}$ State Ethnic Affairs Commission, The Chinese Communist Party's Basic Standpoints and Policies on the Nationalities Question (Readings for Cadres) [Zhongguo gongchandang guanyu minzu wenti de jiben guandian he zhengce (ganbu duben)], 2002, p. 155. 
is actively solicited and sought, once policy is decided by the centre, Party institutions and members have an absolute duty to carry it out, and the "minority is subordinated to the majority" ${ }^{105}$ It also means that Party policy remains paramount in all fields, regardless of what formal non-Party institutions may have decided, or what laws may say. As the preamble to the 2002 CCP Constitution concludes: "Leadership by the Party means mainly political, ideological and organizational leadership... Acting on the principle that the Party commands the overall situation and coordinates the efforts of all quarters, the Party must play the role as the core of leadership among all other organizations at the corresponding level."

A principal way in which the Party dominates state institutions is through the so-called nomenklatura system. Under this system, the Party's organization departments at various levels control a list of positions in state bodies, with most specifically reserved for Party members. At the pinnacle of this organizational edifice is the list of 4,000 posts which the Central Committee and its organization departments are responsible for filling and supervising. In addition, there is a secondary list that includes posts in many public institutions (schools, hospitals, associations, etc.) and enterprises, for which appointments are to be reported to the centre. ${ }^{106}$

Thus the allocation of many key appointments within autonomous areas is controlled by the relevant Party committees. However, this does not mean there can be no negotiation over the number of posts subject to the nomenklatura or the candidates for such posts. Appointments are increasingly a subject of negotiation between the centre and the localities. ${ }^{107}$ By the late 1990s, there were a number of non-CCP members serving in relatively high positions, such as provincial vice-governors, due to "a genuine effort" by the CCP to promote such people. ${ }^{108}$

However, accepting non-Party members and accepting people who do not share the CCP's view of certain issues are two different matters. The lack of commitment to ensuring representation of minorities in the Party hierarchy at local level has been a cause of significant friction between central authorities and minority representatives in the PRC. At the annual NPC meeting in 1997, simmering tensions reportedly erupted in meetings between central leaders and minority representatives, and one of their key demands was that minority cadres be appointed

\footnotetext{
${ }^{105} 2002$ Chinese Communist Party Constitution, Article 10.

106 Brodsgaard and Zheng, supra note 97.

${ }^{107}$ J. Burns, 'Strengthening Central CCP Control of Leadership Selection: The 1990 Nomenklatura', 138 China Quarterly (1994) p. 458.

${ }^{108}$ Cheng Li, 'Jiang Zemin's Successors: The Rise of the Fourth Generation of Leaders in the PRC', 161 The China Quarterly (2000) pp. 26-27.
} 
Party chiefs in autonomous areas. ${ }^{109}$ As mentioned above, during the drafting of the 1982 Constitution there were proposals that a much larger number of posts in autonomous areas be reserved for minority members.

Party control is exerted not only through individual members, but also through the formation of cells within institutions. Any organization with three or more Party members must create a Party cell. Regardless of their own personal beliefs, Party members are required to ensure that the Party line is adhered to in the work of their institution.

\subsubsection{Effects of CCP Dominance on Exercise of Autonomy}

In the context of the autonomous areas, any special powers granted to national autonomous areas by the legal framework must be understood in a context of Party dominance of decision-making, and the fact that Party leaders in the autonomous areas, who are mostly Han Chinese, generally outrank their minority counterparts. Figures from 1990 indicate that while 40 per cent of the officials in the TAR government and 54 per cent of deputies in the TAR People's Congress were Tibetans, they made up only 22 per cent of the Party Committee. ${ }^{110}$ It is an unwritten rule that above county level, the Party secretary of any autonomous area should be Han. This is a considerable impediment to the functioning of autonomy in practice ${ }^{111}$ In fact, some commentators believe that due to such factors the TAR enjoys the least amount of autonomy of any Chinese province or region. ${ }^{112}$

In addition, the $\mathrm{CCP}$ does not allow its members to practice religion, a requirement that restricts the recruitment of Tibetan cadres and Party members. Most Tibetans believe strongly in Buddhism and religion is an integral part of Tibet's unique culture. ${ }^{113}$ In the 1990s, the CCP apparently took a more active approach toward securing the loyalty of Tibetan Party members

\footnotetext{
109 J. T. Dreyer, China's Political System: Modernization and Tradition (2004) p. 309.

${ }^{110}$ He Baogang, 'The Chinese Commitment to the Autonomy of Tibet: Theory and Reality', in Tibetan Autonomy and Self-Government: Myth or Reality?, Tibetan Parliamentary and Policy Research Centre, 2000, p. 163.

${ }^{111}$ Mackerras, supra note 14, p. 26.

112 Rabgey and Sharlho, supra note 10, p. 39.

${ }^{113}$ C. Mackerras, People's Republic of China: Background Paper on the Situation of the Tibetan Population, a Writenet Report commissioned by the United Nations High Commissioner for Refugees, Protection Information Section, February 2005, p. 16. Mackerras quotes a 1996 survey on the religious beliefs of Tibetans in the TAR, Qinghai and Sichuan.
} 
and ensuring that they did not believe in Buddhism, although they were allowed to attend some religious events. ${ }^{114}$

Local legislative powers both generally and in autonomous areas are also limited by Party influence. A 1991 document entitled "Certain Opinions on Strengthening the Party Leadership over the Legislative Work" is a key text for understanding the CCP's role in this regard. According to this document, Party intervention is possible in four circumstances: 1 . the Politburo and CCP Congress should review any constitutional amendments and major laws before they are submitted to the NPC; 2. CCP approval is needed for the drafting of any laws covering political matters; 3 . draft laws covering political matters and drafts of major economic and administrative laws should be approved by Politburo members before they are deliberated by the NPC; and 4. the Party exercises "unified leadership" over legislative work. This leadership has four dominant organizational forms: 1. organizational penetration of the NPC leadership and control over NPC appointments; 2. controlling meeting agendas; 3 . organizational oversight over the drafting process; and 4. pre-approval of draft laws by the Politburo. Party members make up more than 70 per cent of PC representatives and they are required to abide by Party rules and the Party line. "In principle no law should be in conflict with the Party's interests and/or inconsistent with Party policy." 115

This pattern also applies to provincial legislative work. Zou argues that in recent years the trend has been for the Party to relax control over government and tighten control over legislative bodies as a way of realizing its policies through legal procedures. ${ }^{116}$ Another view is that in the PRC the traditional Leninist party-state system has been transformed into one "in which the Party is allied simultaneously with the executive and legislative branches". ${ }^{117}$

According to Qin, a dominant role is assigned to the CCP in finalizing autonomy legislation. Once drafting of any autonomy regulation is completed at autonomous region level, he writes, the local Party Committee has to submit it to the CCP Central Committee for review, and the Party centre plays the role of consulting various parties on the draft. Only when consensus has been reached between the Party centre, central government agencies and the

\footnotetext{
114 Shakya, cited in Mackerras, supra note 14, p. 48.

${ }^{115}$ Zou, supra note 95, p. 47.

${ }^{116}$ Ibid., p. 48.

${ }^{117}$ Brodsgaard and Zheng, supra note 97, p. 10.
} 
autonomous region will the autonomy regulation be submitted to the autonomous region people's congress for enactment. ${ }^{118}$

\subsection{Local and Autonomous Legislative Powers}

The exercise of legislative powers was historically one of the major features of autonomy in the PRC, since in the 1954 Constitution autonomous areas were the only localities that were granted such powers. During the reform era, however, the PRC has seen an extensive decentralization of power that some argue has created a system of "de facto federalism". ${ }^{119}$ Significant devolution of power to legislate for local affairs has been part of this shift. Such general local legislative authority may also be exercised by autonomous regions, as well as larger cities with autonomous status that have been explicitly granted such powers by the State Council. ${ }^{120}$

By contrast, the nationality autonomous areas' powers to "modify" state policies and laws to suit local needs and to pass autonomy regulations and special regulations are distinct powers unavailable to non-autonomous legislative organs and local governments. They constitute one of the main methods for achieving autonomy in the PRC system. These powers, if exercised to a significant extent, could provide autonomous areas with much greater possibilities to set priorities and implement policies that are different from those set by the central government.

In practice, however, autonomous areas have hardly used their power to modify laws and policies made at higher levels of government. The extent of adaptation and even outright contravention of national laws and policies by ordinary provinces and particularly by special economic zones go well beyond those of the NRA areas.

This section will review the scope of general local legislative powers, the scope of special legislative powers available to NRA areas, and then show how in fact, due to political reasons,

\footnotetext{
${ }^{118}$ Qin Naichang, 'Discussion of the Difficulties in Enacting Autonomy Regulations and New Thoughts on Promoting Minority Legislation - Examples from the Guangxi Zhuang Autonomous Region' [lun zhiding zizhi tiaoli de kunnan ji tuijin minzu lifa de xin silu - yi guangxi zhuangzu zizhiqu wei li], 3 Guangxi Nationalities Institute Journal (Philosophy and Social Science Edition) (1995) p. 6.

${ }^{119}$ Zheng Yongnian, Institutionalizing de facto Federalism in Post-Deng China?, East Asian Institute Working Paper No. 9, August 1998.

${ }^{120} \mathrm{Xia}$ argues that this legislative record increases minority awareness of rights, and may lead to greater pressure for real compliance. Xia, Chunli, 'From Discoursal Politics to Rule of Law: A Constructivist Framework for Understanding Regional Ethnic Autonomy in China', in 14:4 International Journal on Minority and Group Rights 2007.
} 
the former have proved to be of much greater utility than the latter. However, the contrast should also demonstrate that the potential for exercising greater autonomy under the existing system certainly exists, given the right political circumstances.

\subsubsection{General Local Legislative Powers}

The decentralisation of legislative power in the 1982 Constitution was among its major innovations. Article 100 authorizes people's congresses of provinces and municipalities directly under the central government to adopt local regulations, provided these do not contravene the Constitution, national laws, or administrative regulations enacted by the State Council. Local regulations may be made "in light of the specific conditions and actual needs of their respective administrative areas" $" 121$ but cannot modify national laws. Once passed, the regulations are to be reported to the NPCSC "for the record". ${ }^{122}$ Unlike for autonomy legislation, no higher-level approval is necessary. Similar powers have been granted under specific State Council authorization to the five special economic zones (SEZs) and to certain larger cities.

As provincial-level units, the five autonomous regions are automatically eligible to exercise this constitutional power of local law-making; Article 115 of the Constitution makes clear that autonomous areas enjoy the general powers of local governments as specified in Chapter III, Section V, as well as their autonomy powers.

The SEZs arguably have greater legislative power than autonomous regions. They have been authorized under specific NPCSC decisions ${ }^{123}$ to enact local regulations as long as these

\footnotetext{
${ }^{121}$ Article 64 of the Legislative Law provides for local legislation to cover three types of situations: 1) to implement a law or administrative regulation in the particular circumstances of a locality; 2) to cover matters of local concern "for which enactment of a local regulation is required"; and 3) to cover matters for which no national law or administrative regulations yet exist.

${ }^{122}$ According to the Legislative Law all local laws and regulations must be deposited with the NPCSC or another relevant depository organ such as the State Council or the provincial people's congress within 30 days.

${ }^{123}$ July 1992 NPCSC Decision Authorizing the People's Congress of Shenzhen City and its Standing Committee and the People's Government of Shenzhen City to "formulate, in light of the specific conditions and actual needs and pursuant to the provisions of the Constitution and the general principles laid down in laws and administrative regulations and rules, regulations to be implemented in the Shenzhen Special Economic Zone which shall be submitted to the Standing Committee of the National People's Congress, the State Council and the Standing Committee of the People's Congress of Guangdong Province for the record, and that the People's Government of Shenzhen City is authorized to formulate rules and is responsible for their implementation in the Shenzhen Special Economic Zone". 1996 Decision of the NPCSC on Authorizing the People's Congresses of Shantou City and Zhuhai City and their Standing Committees and the People's Governments of Shantou City and Zhuhai City to Formulate Regulations and Rules Respectively for Implementation in the Shantou and Zhuhai Special Economic Zones.
} 
comply with the "general principles" of national laws. In practice, this has been interpreted to allow SEZs to enact regulations that actually contradict national and provincial legislation. One reason is that no legislative (or other authoritative) interpretation exists on the meaning of the "general principles" of national law. ${ }^{124}$

Inconsistencies between local laws passed by provincial people's congresses and national legislation are common. ${ }^{125}$ There is no effective scrutiny of the compliance of general local regulations with the Constitution and other laws and the process of submitting local legislation to the NPCSC for the record (bei an) is not subject to much control. ${ }^{126}$ The NPCSC is not known to have ever exercised its power to repeal local legislation. Many local areas do not even report their regulations to the relevant bodies. ${ }^{127}$

The volume of such legislation indicates the scale of the problem of conflict of laws in the PRC system. An article on local legislation states that by 2001 more than 7,000 pieces of local legislation had been enacted, with this figure not including autonomy regulations and special regulations passed by autonomous areas. Over half of currently effective local legislation concerns regulation of the economy. ${ }^{128}$

\subsubsection{Special Autonomous Legislative Powers ${ }^{129}$}

The special legislative powers of the people's congresses in national autonomous areas are governed by Articles 115 and 116 of the Constitution. The former states that the "organs of autonomy" of autonomous areas may exercise autonomy powers "within the limits of their authority as prescribed by the Constitution, the Law of the People's Republic of China on

\footnotetext{
${ }^{124}$ Lin, supra note 89 , p. 154.

${ }^{125}$ Zou, supra note 95 , p. 49.

${ }^{126}$ Chapter V of the 2000 Legislative Law provided much more detail on the depository system and the powers of higher level organs to send back or overturn local legislation. However, to date this system has apparently had little effect. In 2004, a new committee was established within the NPC Legislative Affairs Commission to deal with questions of conflicts between local legislation and the Constitution or laws, but review of local legislation is only conducted if there is a complaint. See Xinhua, 'New Body to Address Law Conflicts', China Daily, 21 June 2004.

${ }^{127}$ Zou, supra note 95 , pp. 51-52.

${ }^{128}$ News and Information Office of the NPCSC Secretariat, Legislative Work of the Local People's Congresses in the Last 20 Years [difang renda 20 nian lai de lifa gongzuo], 3 January 2001, available at:

$<$ www.npcnews.com.cn/gb/paper12/1/class001200001/hwz64637.htm>.

${ }^{129}$ For a detailed description of these powers, see Y. Ghai and S. Woodman, 'Unused Powers: Contestation over Autonomy Legislation in the PRC',82:1 Pacific Affairs: Spring 2009.
} 
Nationalities Regional Autonomy and other laws" in order to "implement state laws and policies in the light of the existing local situation". The latter provides:

\begin{abstract}
The people's congresses of national autonomous areas have the power to enact regulations on the exercise of autonomy and other separate regulations in the light of the political, economic and cultural characteristics of the nationality or nationalities in the areas concerned. The regulations on the exercise of autonomy and other separate regulations of autonomous regions shall be submitted to the Standing Committee of the National People's Congress for approval before they go into effect. Those of autonomous prefectures and counties shall be submitted to the standing committees of the people's congresses of provinces or autonomous regions for approval before they go into effect, and they shall be reported to the Standing Committee of the National People's Congress for the record.
\end{abstract}

An autonomy regulation (zizhi tiaoli) may be defined as "a regulation passed by the people's congress of a national autonomous area that deals with basic issues relating to the autonomy of the autonomous area and to important matters of general concern there". ${ }^{130}$ It may also be considered "a comprehensive regulation on autonomy" covering relations between nationalities in the area and relations between the autonomous area and the higher level state organs. However, it cannot regulate other social relationships beyond those between nationalities in the area, and it can only partially regulate relations between the autonomous area and higher level state bodies. $^{131}$

Special regulations (danxing tiaoli), while covering the same potential ground as an autonomy regulation, only deal with one specific area in any particular instrument and thus are more specific in character. ${ }^{132}$ In other words a special regulation can cover particular issues relating to autonomy in an autonomous area. ${ }^{133}$

In addition to passing autonomy and special regulations, under specifically delegated powers people's congresses in autonomous areas can enact modification rules (biantong guiding) and supplementing rules (buchong guiding). ${ }^{134}$ At least 12 national laws specifically allow for

\footnotetext{
${ }^{130}$ Cai, supra note 29, p. 392; Shi Wenzheng and Bu Xiaolin, 'Legislation in National Autonomous Areas', in J. M. Otto et al. (eds.), Law-Making in the People's Republic of China (2000) p. 134.

${ }^{131}$ Ao Junde and $\mathrm{Wu}$ Zongjin (eds.), Theory and Practice of China Nationalities Legislation [zhongguo minzu lifa lilun yu shijian] (1998) pp. 394-395.

${ }_{132}^{132}$ See ibid., p. 399, and Shi and Bu, supra note 130, pp. 135-136.

${ }^{133}$ Cai, supra note 29, p. 392.

${ }^{134}$ Ao and Wu, supra note 131, pp. 401-406.
} 
modification by autonomous areas. ${ }^{135}$ Any one modification rule may apply to only one law or policy document. Both of these types of regulations must be approved by higher level state organs. ${ }^{136}$ Modification rules authorize the flexible implementation of a higher level law, regulation or regulatory document, or a halt to its application in an autonomous area. Thus these may be enacted to waive the application of laws, regulations and government policy documents of various types. While an autonomy regulation or special regulation might effectively supplement an existing higher level legislative instrument it will do so in a general sense, whereas a supplementing rule will be highly specific in nature. ${ }^{137}$

Unlike general local legislation, all autonomy legislation requires either approval by the NPCSC (for autonomous regions) or by provincial level PCSCs (for autonomous prefectures and counties). The difference may be explained by the principle that wherever modification is allowed (ke biantong yuanze), approval is necessary. ${ }^{138}$

Qin argues that since it requires NPCSC approval, autonomy legislation from autonomous regiohns should be have the same status as State Council enactments submitted to the NPCSC for approval and passed by the NPCSC, and thus they should bind national institutions in a way that local legislation does not. "[Autonomy regulations] have the character of local legislation, but they also have the character of national legislation."

\subsubsection{Scope of NRA Legislative Flexibility}

The "modification power" (biantong quan), based on Article 115, is considered by some scholars to be the most important power of autonomous areas. ${ }^{140}$ However, the scope of this power is not very clearly delineated. To date, the most comprehensive legal statement of the scope of autonomy regulations and special regulations is in Legislative Law 66.ii:

\footnotetext{
${ }^{135}$ These include the Criminal Law, Marriage Law, General Principles of Civil Law, Civil Procedure Law, Inheritance Law, Forests Law, Prevention of Communicable Diseases Law and National Flag Law.

${ }^{136}$ As passed in 1980, the Marriage Law did not require such approval, but when it was revised in 2001, an approval process was put in to bring it in line with other laws delegating such powers.

${ }^{137}$ Ao and Wu, supra note 131, pp. 401-406.

${ }^{138}$ Cai, supra note 29, pp. 392-393.

${ }_{139}^{139}$ Qin, supra note 118 , p. 6.

${ }^{140}$ Ibid., pp. 391-392.
} 
Autonomy regulations and special regulations may adapt the provisions of laws and [State Council] administrative regulations to the particular needs of the nationality of the area, but this adaptation must not contradict the basic principles of the laws and administrative regulations, and must not contradict the provisions of the Constitution and the [LRNA] or of other relevant laws and administrative regulations with particular application to nationality autonomous areas.

The Legislation Law states in Article 78 that "[t]he Constitution is the highest legal authority; no law, administrative regulation, local regulation, autonomous regulation, special regulation or administrative or local rule may contravene the Constitution" (emphasis added). Article 81, however, specifies that the provisions of autonomy regulations or special regulations on flexibly interpreting a higher level law or regulation will prevail in the autonomous region as will local regulations in an SEZ.

There is greater scope for flexibility in implementing national policies, as opposed to laws, although approval for this is also required. Article 20 of the LRNA provides that

[i]f a resolution, decision, order or instruction of a state organ at a higher level does not suit the conditions in a national autonomous area, the organ of self-government of the area may either implement it with certain alterations or cease implementing it after reporting to and receiving the approval of the state organ at a higher level; the state organ at a higher level shall give the reply in 60 days since the day on which the report is received.

In addition, the LRNA provides that "[o]n the principle of not contravening the Constitution and the laws, the organs of self-government of national autonomous areas shall have the power to adopt special policies and flexible measures in the light of local conditions to speed up the economic and cultural development of these areas" (Article 6(ii)).

According to Ao and $\mathrm{Wu}$, the following principles on the permissible scope of modification have emerged from law and practice:

1. Constitutional provisions are not subject to flexibility.

2. Provisions of the LRNA are not subject to flexibility.

3. Where laws already make provision for minority issues, no further modification is allowed regarding their subject matter. For example, the PRC Election Law for the NPC and local people's congresses which makes specific provisions for elections in minority areas is not subject to modification. 
4. Where modification is authorized by particular laws, this should not go against the "basic principles and spirit" of these laws.

5. "There is no need for modification, and there should not be any, regarding all laws and administrative regulations that are already in accord with the "particular political, economic and cultural characteristics of the minority in that area' and where there is already no impediment to their implementation in that area." ${ }^{141}$

\subsubsection{Autonomous Legislative Powers Underused}

In general, the autonomous areas have not made much use of their special legislative powers to enact autonomy and special regulations or modification rules. None of the five autonomous regions has enacted an autonomy regulation or special regulation, although all five have drafted autonomy regulations. ${ }^{142}$ According to a minority scholar from Guangxi, this state of affairs "is not beneficial to the exercise of autonomy powers by the autonomous areas, and affects the development of the economy and culture of nationality autonomous areas". ${ }^{143}$

By contrast, many subprovincial autonomous areas - including some Tibetan areas - have enacted autonomy regulations and special regulations. According to Ao and $\mathrm{Wu}$, of the nine laws that authorized modification rules at the time of their writing in 1998, such rules had only been enacted in relation to three: the Marriage Law, the Inheritance Law and the Election Law. To date, autonomous regions have only passed modification rules relating to the Marriage Law and Adoption Law. Modification rules related to provincial legislation have only been enacted in relation to four such regulations. By 1995, a total of 59 modification and supplementing rules had been enacted by NRA areas. ${ }^{144}$.

The TAR People's Congress has been particularly inactive in comparison to the other provinces and autonomous regions. A report on the work of the TAR People's Congress from 1998 until 2003 mentions only one piece of legislation passed under the autonomy powers: a

\footnotetext{
${ }^{141}$ Ao and Wu, supra note 131, pp. 410-411.

${ }^{142}$ Ghai and Woodman, supra note 129, p.38. According to Qin, the GZAR has not passed one special regulation in its 37 year history, and has only made alterations to a small number of laws that specifically allow for these: "This can only be said to be a failing in the construction of the minority legal system." He suggests that ARs could use their general local legislative powers to pass regulations that make alterations to national laws and policies, as other areas have done. See Qin, supra note 118, p. 9.

${ }^{143}$ Qin, supra note 118, p. 2.

${ }^{144}$ Ao and Wu, supra note 131, pp. 402 and 405.
} 
modification rule regarding the Adoption Law. A cursory review of information available from the News and Information Office of the NPCSC Secretariat also indicates the TAR's inactivity compared to other provinces and autonomous regions. ${ }^{145}$ This disparity may be explained by a lack of reporting by the TAR's People's Congress on its activities or on the relatively small size of the TAR's population. However, according to an official site, between 1965 and 2002 the TAR People's Congress enacted 150 local rules and regulations, which is substantially lower than the numbers enacted by other provincial level jurisdictions. ${ }^{146}$

The case of Guangxi is illustrative in this regard. Although the passage of the LRNA "does seem to have increased the legitimacy of minority demands and increased the minority localities' willingness to demand autonomy", ${ }^{147}$ even in the case of Guangxi it has not led to the enactment of autonomy regulations. According to one knowledgeable source, the other four autonomous regions were waiting to see the outcome of the Guangxi efforts to pass an autonomy regulation before trying to get the centre to approve theirs.

Qin's analysis of difficulties in passing autonomy legislation in Guangxi illustrates some of the factors that have blocked the use of autonomous legislative powers. He asserts that despite the provisions of the Constitution and LNRA, the view of many officials at the centre is that autonomy legislation is really no different from ordinary local regulations, and thus can only govern matters within an autonomous area itself, and not the actions of higher level organs. In practice, the State Council has been given an effective veto on autonomy legislation at the autonomous region level. Qin writes that the NPCSC has ceded its approval power to "certain functional departments at the centre, in particular the economic management ministries" because this is the way that the division of interests between local areas and the centre are generally dealt with. This is a reflection of the lack of clear provisions regulating such matters generally. ${ }^{148}$

An account of the drafting of the autonomy regulations for the TAR indicates the role played by the CCP. Drafting began in 1980 under the leadership of the TAR Party Committee, and the draft underwent several rounds of discussion by the TAR Party Committee Standing Committee and the TAR People's Congress Standing Committee and won the support of the

\footnotetext{
${ }^{145}$ In a search of the NPC website in 2005, there were only 12 news reports on the TAR People's Congress but 42 on Inner Mongolia, 59 on Guangxi, 68 on Yunnan, 67 on Guizhou, 62 on Xinjiang, 31 on Ningxia, and 100 on Gansu.

146 "Regional Autonomy" in China's Tibet: Facts and Figures 2002, available at: <www.china.org.cn>.

${ }^{147}$ Kaup, supra note 19, at 116.

${ }^{148}$ Qin, supra note 118, p.8.
} 
NPC Minority Affairs Committee and "relevant central organs". There were a number of exercises soliciting opinions on the draft at consultation meetings and the document went through 15 drafts altogether. ${ }^{149}$ Reportedly none of these were ever even submitted to the State Council for discussion.

The content of the 15th draft included:

1. A preamble emphasizing national unity and asserting that the TAR was an indivisible part of China.

2. Provisions that mainly Tibetans should constitute the personnel of autonomous organs and exercise their proper role as masters, but with appropriate representation of other minorities, and emphasizing the principle that minorities and the Han relied upon each other.

3. Provisions on self-government including:

- An emphasis on the exercise of self-governance, such as setting development plans.

- A detailed series of special policies and flexible arrangements granted by the centre to Tibet.

- Reflection of the contemporary changes in the situation, e.g. the socialist market economy.

- A chapter on religion reflecting the important and particular nature of religion in Tibet. ${ }^{150}$

It is unclear why the draft did not pass, but it was never formally submitted to the NPCSC for approval. Ao and Wu state that, "[i]n sum, the 15th draft of the regulations rather completely reflected the actual situation in Tibet, thus laying quite a good foundation for the draft's eventual transformation into a bill". ${ }^{151}$

The 2001 revisions to the LRNA have created uncertainty, and some scholars speculate that it will still be some time before regional-level autonomy regulations are finalized. In the Tibetan case, the power to make such regulations could provide a structure from which to

\footnotetext{
${ }^{149}$ Ao and Wu, supra note 131, p. 455.

${ }^{150}$ Ibid., pp. 455-456.

${ }^{151}$ Ibid., p. 456.
} 
negotiate specific points. In other words, Sino-Tibetan negotiations could eventually focus on the content of such regulations and whether they could contain provisions guaranteeing greater autonomy and new arrangements for the relationship between the region and the central government.

As mentioned above, autonomy regulations have been enacted at sub-provincial level. ${ }^{152}$ Since these autonomous areas only need to gain approval from the provincial level people's congress for any regulations enacted to give effect to their autonomous powers, in practice they have enjoyed greater legislative flexibility than the autonomous regions. ${ }^{153}$ Ao and Wu list 127 such autonomy regulations passed between 1985 and 1996 as an appendix to their book. ${ }^{154}$

However, available information on sub-provincial autonomy legislation indicates that it is essentially a method of implementing higher level laws and regulations, and does not actually exercise the modification power. ${ }^{155}$ It is a reflection of the fact that these areas do not have ordinary legislative powers; so the autonomy powers are the only ones they may use.

This summary indicates that given the reality of lack of oversight over general local legislation, in practice, as Lin Feng writes, "tighter controls are imposed on the legislative authority of the five ethnic minority regions than on provinces and municipalities directly under the [Central People's Government]. In other words, the five autonomous regions enjoy less legislative autonomy than ordinary provinces directly under the CPG." ${ }^{156}$

\subsection{Regulations and Policy on Religion and Language in Autonomous Regions}

Two areas of particular concern include religion and language, which form key elements of Tibetan cultural identity. The following section will therefore consider the extent of autonomy granted by relevant regulations and enjoyed in practice.

\subsubsection{Religion and Tibetan Identity}

\footnotetext{
152 Ibid., pp. 395-398

153 The 1982 Constitution represented a liberalization in this regard since previous Constitutions had required that all regulations passed by autonomous areas be approved by the NPCSC. Cai, supra note 29, pp. 392-393.

${ }^{154}$ Ao and Wu, supra note 131.

${ }^{155}$ Ghai and Woodman, supra note 129, pp. 41-43.

${ }^{156}$ Lin, supra note 89, p. 157.
} 
There is a strong link between Tibetan Buddhism and Tibetan identity, related to the role of religion in the traditional political structure of Tibetan society. Religion in Tibetan areas is now strongly linked to separatist and self-determination movements by Chinese policymakers. ${ }^{157}$ Much of the religious repression in Tibetan areas reflects attempts to suppress separatist inclinations, and ensure security and unification on the centre's terms. Demonstrations by Tibetans in the late 1980s have been blamed on the liberalization policies of the early-mid 1980s which allowed greater religious freedom, and the demonstrations were followed by a crackdown during the 1990 s. ${ }^{158}$

On the other hand, some officials have reportedly argued that policies to control religious institutions and personnel in Tibet have not achieved their objectives and that repression has actually backfired. Carlson cites an interview with a Chinese scholar - with generally hard-line views on Tibetan policy - who believes that 'Chinese leaders' failure to come to terms with the central role of religion in Tibetan life continued to block the development of successful policymaking in the region". 159

\subsubsection{Regulations Related to Religion}

The 1982 Constitution and the LRNA articulate provisions on freedom of religion for ethnic minorities in China. Article 36 of the Constitution provides for freedom of religious belief and prohibits organizations and individuals from compelling citizens to believe or not to believe in a religion and from discriminating against religious believers and non-believers. It restricts this right, however, to practices that are "normal religious activities" and prohibits the use of religion to "engage in activities that disrupt the public order, impair the health of citizens, or interfere with the educational system of the state". Religious bodies and religious affairs may not be subject to any foreign domination.

\footnotetext{
${ }^{157}$ A. M. Fischer, Urban Fault Lines in Shangri-La: Population and Economic Foundations of Inter-Ethnic Conflict in the Tibetan Areas of Western China, Crisis States Programme, London School of Economics, Working Paper No. 42, June 2004, p. 6.

${ }^{158}$ Rabgey and Sharlho, supra note 10, p. 15 citing 'Zhongyang zhengzhiju changwei taolun Xizang gongzuohui jiyao' (Minutes of Central Politburo Standing Committee Discussion of Tibet Work).

${ }^{159}$ A. Carlson, Beijing's Tibet Policy: Securing Sovereignty and Legitimacy, East West Center, 2004, p. 42.
} 
The specific autonomy provisions in Article 4 and Section VI of the Constitution make no reference to religion, although Article 4 promises the freedom for national minorities to "preserve or reform their own ways and customs".

Article 11 of the LRNA provides that "the organs of self-government of national autonomous areas shall guarantee the freedom of religious belief to citizens of the various nationalities". It then repeats the provisions of Article 36 of the Constitution.

New Regulations on Religious Affairs came into effect in March 2005 which strengthen, and provide more detail on, but do not significantly alter the key principles of existing provisions. ${ }^{160}$ One aim of these regulations is to "further standardize the registration system for the establishment of a religious body or site for religious activities", a practice which has allowed state control over the definition of "normal religious activities". ${ }^{161}$

The 1997 Criminal Law provides that "[w]orkers of State organs that deliberately deprive citizens of their right to religious beliefs or who encroach on minority nationalities' customs or habits, if the case is serious, are to be sentenced to two years or fewer in prison or put under criminal detention". ${ }^{162}$ Other articles in the Criminal Law, however, could limit religious freedoms by imposing penalties on "feudal superstition and superstitious sects". ${ }^{163}$

Sorensen and Phillips observe that China has not adopted legislation agreeing to "[r]espect the rights of minorities to establish and maintain contact with individuals and communities in matters of religion at the national and international levels" in line with international minority rights standards. ${ }^{164}$

Sorensen and Phillips summarize national, regional and local regulations related to religion in the TAR and other Tibetan autonomous areas which are basically implementing measures for national laws and policies and contain some local content. ${ }^{165}$ Key regional provisions include the 1991 Interim Measures of the TAR on the Administration of Religious Affairs; 1991 Interim Provisions of Gansu Province on the Administration of Religious Affairs; 1998 Provisions of

\footnotetext{
${ }^{160}$ Mackerras, supra note 113, p. 16, note 52.

${ }^{161}$ Human Rights in China, China's New Regulation on Religious Affairs: A Paradigm Shift?, 14 March 2005, prepared for a roundtable organized by the US Congressional-Executive Commission on China.

${ }_{162}$ Sautman, supra note 71, p. 303, note 4.

${ }^{163}$ These labels are applied to all religious activities conducted outside the ambit of the five recognized religions and as part of their state-approved institutions.

${ }^{164}$ T. C. Sorensen and D. L. Phillips, Belfer Center for Science and International Affairs, John F. Kennedy School of Government, Harvard University, Legal Standards and Autonomy Options for Minorities in China: The Tibetan Case, 2004.

${ }^{165}$ Ibid., pp. 30-32.
} 
Yunnan Province on the Administration of Religious Affairs; and the 1992 Provisions of Qinghai Province for the Administration of Places of Religious Activity. ${ }^{166}$ These provide for the following rights and limitations:

- Respect for and protection of religious belief and activity.

- Compliance of religious activities with the Constitution and laws.

- Acceptance of Communist Party leadership and support of the socialist system by religious believers and places of worship.

- Government approval for rebuilding or opening a place of religious activity.

- Management of places of religious activity by "patriotic religious groups whose members must support the Party and socialism, be patriotic and law abiding, and safeguard the unity of the State and ethnic groups".

- Prohibition on the use of "religion or places of religious activity ... to incite trouble, create havoc, carry out criminal activities such as separatism, destroy the unity of ethnic groups, or disturb social and public order".

- Quotas for the numbers of monks and nuns in religious institutions in the TAR.

- Requirement that monks and nuns be "patriotic and law abiding".

- Control by the propaganda and publishing departments of religious content in publications.

- Conformity of religious content in publications to state and Party policies.

- Approval required for "editing, publishing, or distributing" religious materials.

- Prohibitions on proselytizing.

- Restrictions on foreign donations to and contacts with religious institutions. ${ }^{167}$

Regional and local regulations on marriage, technology and education also contain provisions related to religious practices.

Although traditional marriage ceremonies are permitted in the TAR and Tibetan autonomous prefectures in Sichuan and Qinghai, religion may not be used to "interfere" with marriage in these locations. ${ }^{168}$

\footnotetext{
${ }^{166}$ Ibid., p. 31, notes 127 and 128.

${ }^{167}$ Ibid., pp. 31-32.
} 
The 1991 Guoluo Autonomy Regulations include a prohibition on the use of religion to "interfere with the promotion of technology" and on coercing "individuals into making contributions to religious institutions". 169

Traditionally, education in Tibetan culture has been religious in nature in contrast to the secularized state education system now imposed on Tibetan areas. ${ }^{170}$ Regulations in the TAR, and some Tibetan autonomous areas in Sichuan, Qinghai and Gansu, prohibit the promotion of religion in schools and the dissemination of superstitious thinking. ${ }^{171}$ The Ganzi Autonomous Prefecture in Sichuan and the Yushu and Guoluo Tibetan Autonomous Prefectures in Qinghai "prohibit school-age children from entering temples and ban religious organizations from recruiting them for religious study". ${ }^{172}$

\subsubsection{Party and Political Influence on Religion in Tibet}

Overall, Party policy reflects fears of separatism and the submission of religion to Party control and its adaptation to socialist society and Party doctrine. ${ }^{173}$ The TAR Communist Party published a document in 1994 articulating this last objective: "Tibetan Buddhism must self-reform ... [and] adapt ... to suit the development and stabilization of Tibet ... Religious tenets and practices which do not comply with a socialist society should be changed." 174

Since the CCP's Third Work Forum on Tibet in 1994 restrictions have been placed on religion, the rebuilding of monasteries, and the numbers of monks and nuns. ${ }^{175}$ This Forum also initiated a Patriotic Education Campaign and Democratic Management Committees were established in monasteries and run by outside officials in order to prevent Tibetan nationalist

\footnotetext{
${ }^{168}$ Ibid., p. 29.

169 Ibid., p. 12.

${ }^{170}$ B. Johnson and N. Chhetri, 'Exclusionary Policies and Practices in Chinese Minority Education: The Case of Tibetan Education', 2 Current Issues in Comparative Education (30 April 2000) p. 4, citing Postiglione, G China's national minority education: Culture, schooling and development. New York: Falmer Press 1999

${ }^{171}$ Sorensen and Phillips, supra note 165, pp. 22 and 23.

${ }^{172}$ Ibid., p. 23. According to Bovingdon, students in Xinjiang are prohibited from professing religious beliefs. If this is also generally true for Tibetan areas, it poses significant restrictions on the right to non-discrimination for religious believing and non-believing citizens. See G. Bovingdon, Autonomy in Xinjiang: Han Nationalist Imperatives and Uyghur Discontent, East-West Center Policy Studies 11, 2004.

${ }^{173}$ Potter, supra note 6, p. 306.

${ }^{174}$ TAR Communist Party, A Golden Bridge Leading to a New Era (1994), quoted in Free Tibet Campaign, Tibet Facts No. 4: Control of Religion, available at: <www.freetibet.org $>$.

175 Smith, supra note 12, p. 19.
} 
impulses and undermine the Dalai Lama's influence. ${ }^{176} \mathrm{~A}$ ban on images of the Dalai Lama instituted in 1996 continues, ${ }^{177}$ and there have been campaigns attacking "the character and integrity of the Dalai Lama". ${ }^{178}$ These measures stem from fears that religion could effectively undermine Party control in minority regions and a belief that religion and religious figures compete with Party authority for people's loyalty. ${ }^{179}$

As discussed in the section on Party influence generally, Party members are not permitted to profess religious beliefs. A 1997 Xinjiang Party Committee Propaganda Bureau Document, although relating specifically to Xinjiang, emphasizes this principle, which is equally applicable to Tibetan Party members:

Ordinary citizens are permitted two freedoms. Though Party members are also citizens, they are first of all members of the party of the proletariat, and therefore enjoy only one freedom - the freedom not to believe and absolutely do not enjoy the freedom to believe. They cannot have feet in two boats. ${ }^{180}$

The CCP United Front Department's Nationalities and Religion Bureau evidently gives high priority to Tibetan Buddhism in its work, with four out of six departments devoted to Tibetan issues and only one department assigned to the remaining 54 minority groups. ${ }^{181}$

According to the State Council's 1997 White Paper on Freedom of Religious Belief in China, the Central Government has contributed large sums for the restoration and building of monasteries and other religious institutions.

Ragbey and Sharlho argue that a complicating factor in relations between Tibetan areas and Chinese authorities has been the growing interest of Han Chinese - both inside and outside of China - in Tibetan Buddhist practices. They contend that Chinese officials exert particular control over monasteries that attract Chinese worshippers and cite as an example a crackdown in 2001 on the Serthar Buddhist Institute in eastern Tibet. ${ }^{182}$

\subsubsection{Language and Cultural Survival}

\footnotetext{
${ }^{176}$ Ibid.

${ }^{177}$ See Mackerras, supra note 113, p. ii and 'The Illusion of Calm in Tibet', 388 The Economist (12 July 2008).

${ }^{178}$ Sorensen and Phillips, supra note 165, p. 45.

${ }^{179}$ Potter, supra note 6, pp. 311-312.

${ }^{180}$ Cited in Bovingdon, supra note 173, p. 35.

${ }^{181}$ Rabgey and Sharlho, supra note 10, p. 32.

${ }^{182}$ Ibid., p. 31.
} 
While the Constitution and the LNRA provide for autonomous areas to use local languages and allow for education in minority languages in schools, in practice the legal equality of minority languages with Chinese is a fiction. But even more important may be the association of Chinese and Han culture with "advanced", modern life and that of minority languages and cultures with "backward", traditional ways. ${ }^{183}$

In the Tibetan context, the Chinese language has become necessary for conducting daily life in the TAR. Despite legal encouragement of bilingualism and use of the Tibetan language, some scholars have observed that Tibetan is actually discouraged "because of its association with the Tibetan nationalist movement", ${ }^{184}$ and that the purpose of official policy is to ensure the appearance of autonomy and therefore greater stability in an unstable region. ${ }^{185}$ In the Huangnan Tibetan Autonomous Prefecture in Qinghai Province, even in institutions devoted to the promotion of Tibetan culture the working language is Chinese, and meetings with a majority of Tibetans were conducted in Chinese. ${ }^{186}$

The TAR People's Congress adopted regulations on the protection of the Tibetan language on 22 May 2002. ${ }^{187}$ They provide that "Tibetan is the common language of the Autonomous Region of Tibet", "Tibetan and Chinese have equal administrative status", "the Chinese and those belonging to other minorities living in the Autonomous Region of Tibet must learn Tibetan" and "those bilingual in Chinese and Tibetan will receive priority in recruitment to administrative positions". These regulations amend earlier provisions from 1987 which required Tibetan children to learn Tibetan. The new regulations allow children and families to choose between using Tibetan or Chinese when attending classes and taking examinations. ${ }^{188}$ The regulations limit Tibetan autonomy with regard to language by emphasizing the "equality" of the Tibetan and Chinese languages.

\footnotetext{
${ }^{183}$ See, for example, Lin Yi, 'Choosing Between Ethnic and Chinese Citizenship: The Educational Trajectories of Tibetan Minority Children in Northwestern China', in V. L. Fong and R. Murphy (eds.), Chinese Citizenship: Views from the Margins (2006).

${ }^{184}$ Johnson and Chhetri, supra note 171, p. 4.

${ }^{185}$ Ibid., p. 5.,citing Lin, J. 'Policies and practices of bilingual education for the minorities in China.' Journal of Multilingual and Multicultural Development, 18 (3), 193-205 (1997).

${ }^{186}$ Lin, supra note 184 , p. 54.

${ }^{187}$ N. Tournadre, 'The Dynamics of Tibetan-Chinese Bilingualism', 45 China Perspectives (2003).

${ }^{188}$ Ibid., p. 31.
} 
In practice, however, even in "minority" junior and senior middle schools, the medium of instruction is Chinese. Any student who has ambitions must focus on learning Chinese, rather than concentrating on Tibetan. ${ }^{189}$

Reports that relations between Han and Tibetan cadres have worsened - seemingly confirmed by ethnically motivated violence in the March 2008 protests - may be due, in part, to language difficulties since Han cadres often make decisions and then use Tibetan cadres as translators - a practice that creates resentment and isolates Han officials from the local population. $^{190}$

\section{Conclusions and Possibilities}

It is not the purpose of this article to suggest or comment on negotiating strategies, but to describe and analyse legal regimes of autonomy. Significant limitations exist in the functioning of the Chinese system of national regional autonomy which could hamper the Tibetans' efforts to achieve their key demands for "genuine autonomy" and the unification of Tibetan areas within the current system. These obstacles include: state priorities of unity, stability, sovereignty, as expressed in the strict suppression of any dissent labelled as "separatist"; Communist Party supremacy; state economic and development priorities, especially in Western regions; weak rule of law, constitutional ideology, and lack of democratic development; the possibly temporary nature and integrationist approach to minority policy (as informed by Chinese culture and Marxist-Leninist theory); and the political realities within Tibet itself of central control and unrealized autonomy.

In addition, the 2004 White Paper leaves little scope for negotiation:

Any act aimed at undermining and changing the regional ethnic autonomy in Tibet is in violation of the Constitution and law, and it is unacceptable to the entire Chinese people, including the broad masses of the Tibetan people.

\footnotetext{
${ }^{189}$ Lin, supra note 184.

${ }^{190}$ Potter, supra note 6, p. 302, citing Sun Yi et. al., 'Issues in Training Minority Cadres and Minority Representatives in Xinjiang' [Xinjiang ... shaoshu minzu ganbu ji shaoshu minzu daibiao renshi wenti], in 1 Collection of Essays on the Study of Xinjiang [Xinjiang yanjiu wenlunxuan] (2003) pp. 309-310.
} 
In light of these limitations, possibilities for achieving Tibetan demands within the current system may seem slim. However, some possibilities may exist and particular points of view within Chinese political and academic circles could be encouraged in order to eventually achieve a better environment for Sino-Tibetan negotiations. Some trends that may present options include:

1. Complexity and larger debate: Rabgey and Sharlho argue that the process of policymaking on Tibetan issues has become increasingly complex, possibly allowing for more diverse views and greater decentralization of the decision-making process. ${ }^{191}$ They also point out that the ramifications of numerous personnel changes within Tibetan policy-making institutions are unclear but may have some positive effects. $^{192}$

2. Ethnic nature and problems with economic development: A greater recognition of the "ethnic" nature of the Tibetan question and the limits of economic development in resolving ethnic tensions may have created space for new approaches to the Tibetan question. Several scholars both inside and outside China ${ }^{193}$ have argued that the policy of increasing economic development in Western China has failed to resolve the Tibet question and may have exacerbated ethnic tensions due to a growing economic gap. The costs involved in subsidizing growth in Tibet, spending on massive infrastructure projects and launching the Great Western Development Campaign have been substantial for the central government. ${ }^{194}$ As a result, there may be a greater willingness to look beyond economic development for solutions.

3. Change of leadership at the top: Although $\mathrm{Hu}$ Jintao previously took a tough approach against separatism in Tibet as the TAR Party Secretary in the early 1990s, this could actually make him less vulnerable to attack from hardliners if he chooses to negotiate with the Tibetans. ${ }^{195}$ Others, however, have observed that his criticisms of Chinese intellectuals in 2004 have cast doubts on hopes that Hu would implement

\footnotetext{
${ }^{191}$ Rabgey and Sharlho, supra note 10, p. 31.

${ }^{192}$ Ibid., pp. 33-35.

${ }^{193}$ Ibid., Sautman, supra note 8.

${ }_{195}^{194}$ Rabgey and Sharlho, supra note 10, p. 26.

195 Sautman, supra note 8, p. 100.
} 
a more liberal political agenda. ${ }^{196}$ It is still unclear how the change of leadership might affect minority policy and Tibetan policy in particular.

4. Tibet's uniqueness: The Chinese government has acknowledged that Tibet has different characteristics from other nationality areas. For example, reference has been made to Tibet's "four uniques": region, culture, significance and treatment. ${ }^{197}$ This could provide justification for special treatment of Tibet within national autonomy arrangements. Although the Chinese government stresses the "system" of NRA, in fact a differentiated approach to different minority groups has been a feature of this system from its inception. One particular issue here could be to allow Tibetan Party members to practice their religion, if they so desire, and to allow religious believers to join the Party.

5. Issue of trust: Recent statements by the Dalai Lama that Tibet would benefit from remaining part of China and his willingness to negotiate within China's constitutional framework could address the previous lack of trust between the two sides. ${ }^{198}$ China's confidence may also increase with greater political stability in Tibet - and in China generally - and allow for a fairer assessment of the risks and benefits of greater autonomy for Tibet without being coloured by an obsessive fear of separatism. ${ }^{199}$

\section{Strengthening legal provisions:}

- Negotiating the terms of autonomy regulations for the TAR as a "Basic Law" for Tibetan areas.

- Strengthening existing "opt-out" clauses - such as the power to amend national laws and policies granted by Article 115 of the Constitution.

- Clarification of certain measures which are currently ambiguous - such as specifying which national laws do or do not apply to Tibet and the extent of

\footnotetext{
${ }^{196}$ Mackerras, supra note 113, p. 31.

${ }^{197}$ Sautman, supra note 8, p. 103.

${ }^{198}$ Perry, A., 'A Conversation with the Dalai Lama', Time Asia Magazine, 25 October 2004, quoted in Mackerras, supra note 113 , p. 15 , note 50.

${ }^{199}$ Mackerras, supra note 113, p. 32.
} 
local legislative power and central or Party supervision over Tibetan autonomy.

- Although the application of Article 31 to the Tibetan case is unlikely, its broad wording could allow some scope for achieving a level of autonomy somewhere between that exercised by Hong Kong and the national regional autonomy system without stressing "one country, two systems". 